\title{
Age of Decision: Pension Savings Withdrawal and Consumption and Debt Response ${ }^{1}$
}

\author{
Sumit Agarwal, Jessica Pan, and Wenlan Qian \\ National University of Singapore
}

January 2015

\begin{abstract}
This paper uses a unique panel of consumer financial transactions to examine how aging consumers respond to the option to cash out retirement savings. To obtain causal identification, we exploit an administrative regulation in Singapore that allows individuals to cash out a fraction of their pension savings at age 55. We find a large and highly significant increase in bank account balances when an individual turns 55, suggesting that the average consumer in our sample withdraws a large portion of their eligible retirement savings. In line with the predictions from the life-cycle/permanent-income hypothesis, we find modest increases (about 9 percent of the increase in account balance) in cumulative total spending twelve months later. This increase is driven largely by an increase in debit card spending and is concentrated among low-liquidity consumers. Consumers also use the increase in disposable income to pay down their credit card debt. We do not find any evidence that the average consumer responds by excessively increasing present consumption at the expense of future financial security. Nevertheless, consumers leave a sizeable portion of their withdrawn savings in low-interest accruing bank accounts for at least a year after withdrawal. We provide some suggestive evidence that consumer demographics, especially those related to financial literacy and sophistication, appear to matter for consumers' withdrawal decisions.
\end{abstract}

Keywords: Aging, Pension Savings, Consumption, Spending, Debt, Credit Cards, Household Finance, Banks, Loans, Durable Goods, Discretionary Spending, Liquidity Constraints, Credit Constraints

JEL Classification: D12, D14, D91, E21, E51, E62, G21, H31, J26

\footnotetext{
${ }^{1}$ Lin Tong provided excellent research assistance. We benefited from the comments of Gene Amromin, Souphala Chomsisengphet, Erik Hurst, David Laibson, Alexander Ljungqvist, Roni Michaely, Neale Mahoney, Jonathan Parker, Ivan Png, Nagpurnanand Prabhala, Tarun Ramadorai, Amit Seru, Nick Souleles, and workshop participants at the American Economic Association, Australian National University, CEPR European Summer Symposium in Financial Markets, Federal Reserve Bank of San Francisco, Federal Reserve Bank of Chicago, IDC Herzliya, National University of Singapore, and Singapore Management University.
} 


\section{Introduction}

Many countries rely on pension savings to meet individuals' retirement needs. ${ }^{2}$ Moreover, with the sole exception of the United States, major developed countries in the world have made their defined-contribution pension system overwhelmingly illiquid before age 55 (Beshears et al., 2015). A key question arises as to whether individuals should be allowed flexible access to pension savings. On one hand, easier access may make pension savings more flexible and attractive, generating more savings overall and higher retirement income. On the other hand, there is concern that access to one's pension savings can result in excessive present consumption at the expense of future retirement security (Beshears, Choi, Laibson, and Madrian 2008). The question becomes more pertinent as countries are discussing or implementing early access options. For example, the UK government announced in the 2014 Budget a nationwide policy change that allows near-retirees (i.e., those reaching age 55) more flexible early access to the defined contribution pension. ${ }^{3}$

Despite the importance of this issue for policy formulation, the evidence remains limited on the reasons for pension saving withdrawal and the usage of these funds, as can be illustrated in the call-for-evidence on early access to pension savings by the UK Treasury in December 2010,

“...Early access to pension savings is one such option. It could encourage more pension savings, or provide flexibility for individuals facing financial hardship. It could give more choice during the accumulation of pension savings, and so complement the reforms to remove unnecessary restrictions on accessing retirement savings in later life. However, early access also poses potential risks to retirement outcomes, and evidence on the likely impact of early access is currently limited...."

A number of studies theoretically and empirically explore early access to pension savings in the U.S. context, which takes the particular form of 401(k) loans. Almost half of the eligible households have withdrawn their pension savings to potentially fund current consumption (Beshears, Choi, Laibson, and Madrian, 2011). In addition, the empirical evidence suggests that demographics (Beshears et al., 2011) and liquidity constraints (Lu, Mitchell, Utkus, and Young, 2014) are important determinants of the withdrawal decision. Nevertheless, due to data constraints, these studies are unable to examine what consumers actually do with these loans. Therefore, a more comprehensive understanding of the actual behavior of early withdrawing individuals is needed to assess the impact of early pension savings access.

In this paper, we exploit an administrative regulation in Singapore that allows individuals to cash out a fraction of their pension savings at age 55. Similar to the U.K., Singapore grants nearretirees access to their pension savings. In addition, individuals in Singapore have a fairly unrestrictive option of early access due to no tax or other costs on withdrawal. This natural

\footnotetext{
${ }^{2}$ For example, see Whitehouse (2007) for an in-depth comparison of retirement-income systems across countries.

${ }^{3}$ In general, individuals from 55 and over will have more flexibility over how much they can access their pension savings (e.g., in the size and the tax rate of the withdrawal). Details can be found in the following link: https://www.gov.uk/government/uploads/system/uploads/attachment_data/file/301563/Pensions_fact_sheet_v8.pdf.
} 
experiment raises some interesting economic questions whose answers are important for understanding how aging consumers make financial decisions. First, do consumers take advantage of the early access option and withdraw from their pension savings? Second, how does it affect the consumption and savings decision of these aging consumers? For example, are the consumption decisions, conditional on withdrawal, consistent with variants of the lifecycle/permanent income hypothesis model (i.e. liquidity constraints and buffer stock models)? Lastly, what motivates the withdrawal decisions of these aging consumers? Do they make such decisions due to liquidity constraints and demand for financial flexibility?

Our empirical strategy exploits monthly individual-level financial data and sharp differences in the access to pension savings caused by age restrictions on when such funds can be withdrawn. Specifically, in Singapore, individuals are allowed to withdraw a portion of their retirement savings when they turn 55. This administrative regulation implies that the ability to access retirement funds increases discretely in the month that individuals turn 55. Since individuals turn 55 at different points in time in our sample, this allows us to compare the consumption and savings responses of individuals who just turned 55, relative to those who are about to turn 55 . Assuming that all observed and unobserved determinants of consumption and savings decisions other than pension savings access are likely to trend smoothly across the age-55 threshold, ${ }^{4}$ any discrete change in consumption and savings at age 55 can be attributed to the access to pension savings. This regression discontinuity strategy, exploiting the age threshold, allows for a causal interpretation of the effects of pension savings access on the consumption and savings responses of near-retirees.

All working Singaporeans and permanent residents are obliged to contribute to the Central Provident Fund (CPF), a compulsory savings plan that can be used to fund an individual's retirement, healthcare, and housing needs. Employees contribute 20 percent of their gross monthly salary while employers contribute an additional 16 percent of the employee's salary to the fund, subject to a monthly cap of SG\$1,000 in dollar contribution. ${ }^{5}$ The pension contribution rate (max at 36\%) may appear high at the first glance, but one salient feature about Singapore is the lack of social security (or other private pension or social safety net) system. By taking into account both the contribution rate for the private pension account and the tax rate of $15 \%$ on social security and Medicare for an average American, the combined contribution rate for retirement and healthcare amounts to around $27 \%$ in the U.S. which is more comparable with

\footnotetext{
${ }^{4}$ This assumes that there are no other institutional features in Singapore that change discretely when an individual turns 55. One potential confounding feature, as discussed in greater detail in Section 5, is the change in the employer and employee CPF contribution rates at several age cut-offs (including 50, 55 and 60; see section C in the Appendix for details). We conduct a series of falsification tests in Section 5.5 that demonstrates that our results are unlikely to be driven by the change in CPF contribution rates at age 55. Besides the age-related change in CPF contribution rates, to our knowledge, there are no other institutional features in Singapore that change discretely in the month an individual turns 55 .

${ }^{5}$ These CPF contribution rates are for prime-age employees (50 years or less). The CPF contribution rates differ slightly for older workers. The rates can be found here: http://mycpf.cpf.gov.sg/Employers/Gen-Info/cpfContri/ContriRates-Sep2012_Dec2013.htm
} 
that in Singapore. ${ }^{6}$ During our sample time period from April 2010 to March 2012, individuals were entitled to withdraw 10 percent to 30 percent of their CPF cash balance upon reaching age $55 .^{7}$ The remaining CPF balances are disbursed to individuals monthly on reaching age 65.

Estimates from the CPF show that among those aged 45 to 54 in 2010, the median CPF balance was $\$ 45,000,{ }^{8}$ indicating that the median consumer could withdraw about $\$ 13,500$ at age 55 . The $25^{\text {th }}$ percentile could withdraw approximately $\$ 2,700$ and the $75^{\text {th }}$ percentile could withdraw $\$ 30,000$. Official aggregate statistics reveal that, indeed, a significant amount out of the pension savings is withdrawn by individuals reaching 55. Roughly one third of qualified individuals withdrew a total of SG\$2.6 - 3.1 billion annually between 2010 and 2012, averaging over SG $\$ 11,000$ per person. ${ }^{9}$ This is all the more remarkable given that there is no social security in Singapore, and CPF is one of the most important vehicles for retirement savings of individuals. To some extent, this is an ideal setting to assess the likely negative impact of early pension savings access, since excessive spending out of the withdrawal will have a direct implication on future financial security due to lack of other social safety nets in this country.

According to a recent survey, conducted by an insurance company in Singapore during the second quarter of 2014, one third of the 500 survey respondents expressed a preference for more flexibility in the CPF withdrawal and about 45 percent of survey respondents would withdraw from their CPF savings at age $55 .^{10}$ In addition, instead of engaging the withdrawal funds for current consumption, those who preferred to withdraw a lump sum would deposit 30 percent into a bank account, use 18 percent to invest in stocks, bonds, or mutual funds, set aside 11 percent for travelling and 10 percent to buy property. The remainder would be used for other purposes, such as to pass on to their children or buy an annuity. Overall, the survey evidence points to the importance of the demand for flexibility in decisions regarding pension savings withdrawal and the subsequent use of funds.

Motivated by the aggregate statistics and survey evidence, our paper provides direct evidence on pension savings withdrawal and the subsequent consumption behavior. Drawing on a unique panel dataset of consumer financial transactions from a large financial institution in Singapore, we examine the response of bank account balances (i.e., a proxy for the withdrawal decision and amount), credit card spending and debit card spending to reaching the withdrawal age. The

\footnotetext{
${ }_{7}^{6}$ See http://www.justfacts.com/socialsecurity.asp for reference.

${ }^{7}$ The proportion of CPF balances that could be withdrawn at age 55 decreased from 30\% in 2010 to $20 \%$ in 2011 and $10 \%$ in 2012. Details of the CPF withdrawal program can be found using the following link and is also summarized in the Appendix. http://mycpf.cpf.gov.sg/NR/rdonlyres/89BB35C5-BBFC-45DD-A0F510F58B15DD90/0/WithdrawalsofCPFSavings.pdf.

8 See CPF Trends, June 2011: http://mycpf.cpf.gov.sg/NR/rdonlyres/EBE95698-8A97-43AD-AF98 F25B62359078/0/CPFTrendsNetCPFBalances.pdf

${ }^{9}$ See http://mycpf.cpf.gov.sg/CPF/About-Us/CPF-Stats, Section D for the aggregate statistics. The total number of withdrawals from the retirement account between 2010 and 2012 is between 240,000 and 280,000.

${ }^{10}$ The survey was conducted by Manulife as part of their quarterly surveys, and details about the survey outcomes can be found here http://www.channelnewsasia.com/news/singapore/just-one-fifth-of/1309454.html?cid=NLCNA.
} 
richness of the data enables us to identify the causal effect of access to pension savings on consumption using a large representative sample of consumers. Furthermore, we can directly study whether there are salient dynamics in the consumption and debt responses in the months before and after an individual is eligible to withdraw a portion of their pension savings.

Credit cards play an important role in consumer finances and can be useful for studying consumer-spending behavior (Gross and Souleles, 2002). As discussed in Agrawal and Qian (2014), consumer credit also plays an important role in Singapore - more than a third of consumers have a credit card, and the total credit card debt as a percentage of GDP was over two percent in Singapore in 2011 (Department of Statistics of Singapore, 2012). Moreover, debit and credit cards are important mediums of disposable consumption in Singapore, with approximately 30 percent of aggregate consumption in the country being purchased via credit and debit cards. ${ }^{11}$ In this paper, we are interested in the consumption and debt dynamics of households resulting from access to pension savings (which generates a large, predictable increase in disposable income); hence, we are particularly interested in credit and debit card usage as these represent an important source of unsecured credit for most households (Japelli, Pischke and Souleles, 1998).

Previewing our results, we find that, on average, as individuals became eligible to cash out a fraction of their retirement savings, their bank balances rose by about SG\$15,000 (approximately 2.5 times that of average monthly income in our sample) one month after they turned 55. This is consistent with the published aggregate statistics on the average withdrawal amount. Cumulative card spending (credit card + debit card) rose by about $\$ 600$ during the twelve months after consumers turned $55 .{ }^{12}$ Most of the spending response was driven by an increase in debit card spending and increased spending of low-liquidity consumers. We find little evidence that highliquidity consumers changed their spending patterns in response to the anticipated increase in disposable income. Both groups of consumers used the increase in disposable income to pay down credit card debt - on average, credit card debt was about $\$ 500$ lower in the twelve months after an individual turned 55. On average, bank account balances declined by about one third after twelve months, with the balance remaining significantly higher (SG\$10,000) even at the end of our sample period. Lastly, in addition to the roles of liquidity constraints and demand for financial flexibility, consumers' demographics, especially those related to their financial literacy and sophistication, appear relevant in understanding their withdrawal decisions. Various

\footnotetext{
${ }^{11}$ The remaining 70 percent of consumption is transacted via checks, direct transfers, and cash. Consumers with recurring payments like mortgages payment, rent payments, and auto loans payments use instruments such as checks and direct deposit. We confirm this using our credit and debit transaction-level data; looking through the transaction category codes, merchant names, transaction types, we do not find a single transaction for mortgage, rent, and auto loan payments in over 18 million debit card and credit card transaction. Hence, we conclude that these reoccurring payments are through checks and direct deposits. We empirically also confirm that these recurring payments conducted using instruments such as checks and direct deposits are not sensitive to transitory income changes. Japelli, Pischke, and Souleles (1998) found that people with bankcards were better able to smooth their consumption past income fluctuations than were people without bankcards.

${ }^{12}$ We also find some evidence of a reduction in consumption volatility after individuals turn 55, consistent with the interpretation of better consumption smoothing. However, the evidence is weak and suggestive.
} 
falsification tests, using un-qualifying individuals around the same age threshold and qualifying individuals around a different age threshold, lend further support to a causal interpretation of our findings.

Access to pension savings does not appear to have a large effect on the consumption patterns of the average consumer (except the liquidity-constrained group), echoing the survey evidence that most people do not intend to consume (much of) the withdrawn funds. On the other hand, we also document a puzzling new finding regarding the withdrawal decision of these aging consumers. Even though they have flexibility on the withdrawal timing and the process is fast and efficient, consumers on average take out the money immediately without spending or investing it in more productive savings vehicles in the one year period. In contrast, consumer financial literacy and sophistication appear to matter beyond the rational incentives.

Our paper is most closely related to the literature on the liquidity of retirement savings. Beshears et al. (2015) document the prevalent illiquidity nature of pension systems in major developed countries in the world. Beshears et al. $(2008,2011)$ and Lu et al. (2014). Beshears et al. (2008, 2011) document the facts, outline the mechanisms, and discuss the wealth effects of the withdrawal of pension savings through $401(\mathrm{k})$ loans in the United States. They show that consumers who withdraw their pension savings using 401(k) loans may make reasonable decisions under some assumptions and that liquidity constraints could explain some of the withdrawal decisions (see also, Weller and Wagner, 2008 and Li and Smith, 2008). Moreover, they show that access to 401(k) loans may allow for consumption smoothing and does not appear to have a large effect on the wealth accumulation of the elderly. Finally they also document significant heterogeneity by household demographics like income, age, tenure, and the use of $401 \mathrm{k}$ loans. Lu et al. (2014) show that liquidity-constrained households are more likely to take out the $401 \mathrm{k}$ loans. However, there is no evidence on the actual consumption and saving behavior after individuals withdraw from their pension savings. In this regard, our findings complement the existing studies by providing new evidence on the causal impact of the early access option on the actual consumption and savings decisions.

Our paper also contributes to the vast literature studying consumption and savings responses of individuals that face expected and unexpected income windfalls (e.g. tax rebates, etc.). ${ }^{13}$ While the standard LCPIH predicts that individuals should not respond to predictable income shocks, the empirical evidence on this issue is mixed. While some studies find that the consumption response is essentially zero, others find that liquidity-constrained consumers respond positively to fiscal stimulus programs. For example, Browning and Collado (2001) argue that in the face of bounded rationality, individuals will smooth consumption in the presence of large and

\footnotetext{
${ }^{13}$ For example, see Shapiro and Slemrod (1995, 2003a, 2003b), Souleles (1999, 2000, 2002), Parker (1999), Hsieh (2003), Stephens (2003, 2006. 2008), Johnson, Parker and Souleles (2006) Agarwal, Liu and Souleles (2007), Stephens and Unayama (2011), Agarwal and Qian (2014), Scholnick (2013) and Parker et al. (2013). For a review of the literature, see Browning and Collado (2003) and Jappelli and Pistaferri (2010).
} 
predictable income changes, but may fail to adjust optimally to small income changes, as the utility cost of doing so is small. We provide direct evidence consistent with this "magnitude hypothesis": although, on average, individuals reaching 55 do not spend their withdrawn funds of SGD 15,000, the same individuals have high MPCS when they receive a stimulus package worth an average of SGD 500 within the sample period.

Finally, our finding that consumers do not invest the unconsumed withdrawn funds at more productive savings vehicles also relates to the literature that documents mistakes over the lifecycle (Choi, Laibson, and Madrian, 2012 and Agarwal, et al. 2009). The first study clearly shows that individuals at retirement leave money on the table. The second paper documents that financial mistakes follow a U-shaped pattern, with the optimal age of financial decision-making reaching a peak at around age 53. Our study highlights the possibility that even though the aging population does not make obviously suboptimal consumption decisions, ${ }^{14}$ their savings decisions may be driven by behavioral factors - consumers in our sample leave a significant amount (SGD 10,000) of withdrawn savings in the low-interest-accruing bank account for at least a year upon withdrawal.

The rest of the paper proceeds as follows. The next section discusses the institutional details of the Central Provident Fund and retirement savings in Singapore. Sections 3 and 4 describe the data and the empirical strategy. The results are presented in Section 5 and the conclusion in Section 6.

\section{The Central Provident Fund and Retirement Savings in Singapore}

The Central Provident Fund is a comprehensive pension savings system in Singapore that covers retirement, healthcare, home-ownership, family protection and asset enhancement. All working Singaporeans and their employers are obliged to make monthly contributions to the CPF that go into three accounts. The Ordinary Account (OA) can be used for housing, insurance, investment, and education, the Special Account (SA) can be used for investment in retirement-related financial products and the Medisave account can be used for hospitalization and approved medical insurance. The exact CPF contribution rates for employees and employers differ by age and over time, but in general, for prime-age working individuals, the employee contribution rate is 20 percent of their gross monthly salary and the employer contribution is approximately 15 percent. The share of CPF contributions allocated to each account also changes over the life cycle of a working individual, in line with their changing needs over time. Approximately 15-25 percent of the CPF contribution is credited to the Special Account exclusively for retirement purposes. A table in section $\mathrm{C}$ of the Appendix shows the CPF contribution and rates of allocation to the various accounts in 2010 .

\footnotetext{
${ }^{14}$ Previous literature shows that, on average, consumers are able to make optimal spending decisions in response to various economic incentives (e.g., Agarwal et al., 2012; Agarwal, Chomsisengphet, Ho, and Qian, 2013).
} 
Upon reaching 55, individuals are entitled to withdraw a portion of their CPF savings based on their available CPF balances. ${ }^{15}$ Part of the remaining CPF balances are used to form a new Retirement Account (RA), and collectively all unwithdrawn CPF accounts typically earn 2.5 percent-4 percent guaranteed interest per annum (since 1999). ${ }^{16}$ Until December 31, 2008, individuals were allowed to withdraw 50 percent of their available CPF balances. At the National Day Rally in 2003, it was announced that the government was planning to gradually phase out the 50 percent withdrawal rule. With rising retirement ages, the government wanted to ensure that CPF savings were not depleted prior to when individuals actually retired. To allow CPF members sufficient time to adjust to the new changes, these changes were phased in gradually. Five years after the announcement, starting from 2009, the amount that could be withdrawn at 55 was reduced gradually by 10 percent each year. ${ }^{17}$ These changes in withdrawal rates were announced at the National Day Rally in 2003 (five years before any changes were implemented); hence it is reasonable to assume that these changes were fully anticipated.

The CPF board typically sends individuals an advance withdrawal invitation with details on the withdrawal procedure about two months before their $55^{\text {th }}$ birthday. Monthly talks (in multiple languages) are held at the CPF board to explain the withdrawal option for those reaching 55. Upon application, the processing time typically ranges from two to ten working days, and the receipt of the withdrawal is through direct transfer to the designated bank account of the member (and the member only). CPF withdrawals are not subject to income tax. Individuals can withdraw any time after turning 55. If an individual has withdrawn partially from the full eligible sum during the year they turn 55, they will still be eligible to withdraw yearly, on or after their birthday each year. The remaining CPF balances are disbursed to individuals monthly on reaching age 65 (drawdown age). More details on the CPF and the withdrawal option can be found in the Appendix. ${ }^{18}$

\footnotetext{
${ }^{15}$ The withdrawal rule at age 55 is partly historical - when the CPF system began in 1955, members were allowed to withdraw a lump sum at age 55, which was then the retirement age in most private companies. With rising retirement ages, the government introduced the Minimum Sum (MS) and 50\% withdrawal rule starting in 1987. The MS would provide post-retirement payments to the individual. The idea was to safeguard retirement savings to ensure they were not exhausted before an individual actually retires. More details on the CPF policy can be found in Tan (2004). Technically, the withdrawal of the CPF cash balances is also dependent on whether an individual has met the Minimum Sum (MS). The MS applicable during our sample period can be found here: http://mycpf.cpf.gov.sg/CPF/my-Cpf/reach-55/Reach55-2.htm. Note in 2010-2012 (our sample period), if an individual has CPF cash balances in excess of the minimum sum, they are entitled to withdraw all funds in excess of the MS. Individuals with total cash balances less than the minimum sum can still withdraw $10-30 \%$ of the available cash balance.

${ }^{16}$ The Ordinary Account currently pays interest of $2.5 \%$ per annum while the Special Account, Medisave Account and Retirement Account pay interest of $4 \%$ per annum. More details on the interest rates across different CPF accounts can be found in the Appendix.

${ }^{17}$ Tan (2004) provides a concise summary of the historical role of the CPF and the major changes initiated in 2003.

${ }^{18}$ There are also a number of studies that look at the CPF account structure in Singapore and the associated investment implications (Koh, Mitchell, Tanuwidjaja, and Fong, 2007; Koh, Mitchell, and Fong, 2008, 2011; Koh and Mitchell, 2010).
} 
Publicly released aggregate statistics show that close to SG\$3 billion in pension savings is withdrawn each year, amounting to about 1 percent of 2011 GDP in Singapore. ${ }^{19}$ Withdrawing individuals on average cash out SG\$11,000 per person, almost triple the average monthly salary of the population. ${ }^{20}$

\section{Data}

We use a unique proprietary dataset obtained from Singapore's leading bank, which has more than four million customers, or 80 percent of the entire population of Singapore. The entire data set obtained from the bank contains consumer financial transactions between April 2010 and March 2012, including credit card and debit card transactions of more than 180,000 individuals, which is a random, representative sample of the bank's customers. For individuals in our sample, we have monthly statement information about each of their bank accounts, credit cards and debit cards with the bank. The information includes the balance, total debit and credit amount (for bank accounts), spending (for credit and debit cards), and credit limit, payments and debt (for credit cards). ${ }^{21}$ The data also contains disaggregated transaction-level information about the individual's credit card and debit card spending, including the transaction amount, transaction date, merchant name, and merchant category. The data also contains a rich set of demographics about each individual, including age, gender, income, property type (public or private housing), property address, postal code, nationality, ethnicity, and occupation. ${ }^{22}$

This data set offers several key advantages. Relative to traditional household spending data sets in the United States such as the Survey of Consumer Finance (SCF) or Consumer Expenditure Survey (CEX), our sample is larger with little measurement error, and allows high frequency analysis. Compared to existing studies that use micro-level credit card data (e.g. Gross and Souleles 2002, Agarwal et al. 2007, Aaronson et al. 2012), this data set has more complete information on the consumption of each individual in the sample. For example, rather than observing a single credit card account, we have information on every credit card, debit card, and

\footnotetext{
${ }^{19}$ More detailed information can be found at the CPF website: http://mycpf.cpf.gov.sg/CPF/About-Us/CPFStats/CPF_Statistics_SectionD.htm

${ }^{20}$ The average individual monthly income in Singapore in 2012 was \$3,070.

21 The specific banking products that we study (credit card, debit card, and bank checking account) are similar to those used in the United States. Consumers are typically eligible to obtain a bank checking account, and they can conduct banking transactions using branches, Automatic Teller Machines (for cash withdrawals, transfers, or bill payment), checks, or online methods. The typical banking fees and other costs are quite standard, similar to those of a typical US bank, and moreover they are comparable with banking costs at other major banks in Singapore. Debit cards are linked to the bank account, and debit card transactions are drawn on the bank account balance. Similarly, credit cards are granted upon application to consumers who have met the bank's criteria (e.g., income, age, and credit profile). One interesting difference for credit cards is that all credit card holders with the bank have the same prevailing interest rate of $24 \%$ per annum, regardless of the credit card limit. The other important observation is that savings in bank accounts in Singapore typically accrue at close to zero interest rates. For example, various types of accounts in our bank have a maximum of $0.1 \%$ annual interest rate, and thus we aggregate the balance across all bank accounts for the same individual.

${ }^{22}$ Unlike the United States, where a zip code represents a wide area with a large population, a zip code in Singapore represents a building. A unique zip code is assigned to a single house or a building with 10 apartment units.
} 
bank account that each individual has with the bank. One important limitation of our data is that we do not have information about accounts individuals have with other banks in Singapore. Nevertheless, it is likely that the measurement error is minimal given the market share of the bank. For example, an average Singaporean consumer has three credit cards, which is also the number of credit cards an average consumer has in our data set. Hence, we are confident that we are picking up practically the entire consumption of these households through the spending information on the various accounts at this bank. Furthermore, the richness of the individual demographic data and transaction-level information allows us to better disaggregate heterogeneity in consumers' consumption upon reaching the withdrawal age.

Similar to Agarwal and Qian (2014) that uses the same dataset to analyze a different question, we aggregate the data at the individual month level. Credit card spending is computed by adding monthly spending over all credit card accounts for each individual. Credit card debt is computed as the difference between the current month's credit card payment and the previous month's credit card balance. Debit card spending is computed by adding monthly spending over all debit card accounts for each individual. For the bank account, we compute the aggregate number of debit (outflow) transactions for each individual every month. We restrict the main sample to Singaporeans who turned 55 in the sample time frame (March 2010 to April 2012). We further exclude dormant/closed accounts that remained inactive (i.e. with no transactions in at least six months in our 24-month sample period). For the purpose of our study, we restrict the sample to Singaporeans who hold all accounts with this bank (bank account, credit card, and debit card) as these individuals are more likely to have an exclusive relationship with the bank. For these consumers, the withdrawal of retirement savings as well as spending and debt responses can be better identified. Nevertheless, our main results are robust to our sample selection criteria.

Figure 1 provides the summary statistics of the main financial and demographic information for the individuals in our sample by age (in year-months). In the cross-section of individuals, the average bank account balance in the months before 55 is about $\$ 47,500$. Figure $1 \mathrm{~A}$ provides strong suggestive evidence that bank account balances are significantly higher for individuals just over 55 than those just below. Individuals on average have extra savings of $\$ 10,000$ in the month turning 55. Figure 1B shows that, in our sample, the average monthly spending in credit and debit cards in the months before age 55 is approximately $\$ 1,000$. We find some evidence that spending begins to rise for individuals just prior to turning 55 . Spending among individuals older than 55 remains slightly higher than for individuals younger than 55 . Figure $1 \mathrm{C}$ shows the patterns of monthly credit card debt by age - monthly credit card debt declines from about $\$ 1,200$ to $\$ 1,000$ for individuals aged 52.5 years to 54.5 years. Among individuals six months prior to turning 55, we observe a gradual increase in debt, followed by a sharp decline in debt of about $\$ 300$ among individuals who have just turned 55. Overall, it appears that the magnitude of the consumption and debt response is small relative to the large increase in account balances. Even though these results are simple cross-sectional comparisons of different individuals, the jumps in account balance, spending and debt at the $55^{\text {th }}$ birth month are striking. These patterns 
are unlikely to be the result of spurious differences among individuals as we might expect individuals who are 54 years and 11 months old to have observable and unobservable characteristics similar to those of individuals who are 55 years and one month old, on average. Therefore, this provides the first piece of evidence that individuals respond strongly to the withdrawal option, which, in turn, appears to have a small effect on their consumption and debt behavior in the months that follow.

\section{[Insert Figure 1 about Here]}

Figures $1 \mathrm{D}$ to $1 \mathrm{G}$ depict the key demographic variables. The average monthly income in our sample is about $\$ 6,500$ for individuals at age 52 and declines gradually over time to about $\$ 5,900$ for individuals at age 57. On average, our sample comprises approximately 40 percent female, 63 percent married individuals and 88 percent Chinese. Importantly, the figures suggest that these demographic characteristics do not change sharply at age 55, in contrast to the sharp change observed at the same threshold in account balance, spending and debt variables. This suggests that our analysis is unlikely contaminated by other potential "treatments" at the $55^{\text {th }}$ birth month threshold.

\section{Empirical Strategy}

On the day that they turn 55, individuals in our sample are entitled to withdraw between 10 percent and 30 percent of their CPF cash balances. The withdrawal rates applicable to different individuals in our sample are summarized in the table below:

\begin{tabular}{|c|c|}
\hline The day you turn 55 & Withdrawal of cash balances \\
\hline 1 Jan - 31 Dec 2010 & $30 \%$ \\
\hline 1 Jan - 31 Dec 2011 & $20 \%$ \\
\hline 1 Jan - 31 Dec 2012 & $10 \%$ \\
\hline
\end{tabular}

We examine the response of bank account balances, credit and debit card spending and debt to reaching the withdrawal age. Our empirical strategy exploits monthly individual-level data and the fact that the withdrawal age is birthdate-specific. To estimate the average response, we begin by estimating the following model:

$$
Y_{i, t}=\delta_{t}+\alpha_{i}+\gamma W_{i,(-3 m,-1 m)}+\beta W_{i,(0 m, 12 m)}+\epsilon_{i, t}
$$

The dependent variable $Y_{i, t}$ represents the dollar amount of the bank account balance, total card spending, debit card and credit card spending and credit card debt held by individual $i$ at the end of month $t$. $\delta_{t}$ represents a vector of year-month fixed effects and $\alpha_{i}$ represents a vector of individual fixed effects. We cluster the standard errors of our estimates at the individual level. $W_{i,(-3 m,-1 m)}$ is an indicator variable for the one to three months before an individual turned 55 and $W_{i,(0 m, 12 m)}$ is an indicator variable for the zero to 12 months after an individual turned 55 in 
our sample. The absorbed period includes the fourth and earlier months before individuals turn 55 , the benchmark period against which our estimated response is measured.

To analyze the dynamic responses, we estimate the following distributed lag model:

$$
Y_{i, t}=\delta_{t}+\alpha_{i}+\sum_{s=1}^{3} \gamma_{s} W_{i, t+s}+\sum_{s=0}^{12} \beta_{s} W_{i, t-s}+\epsilon_{i, t}
$$

where $W_{i, t}$ is an indicator variable for whether the holder of account $i$ turned 55 in month $t$.

Our empirical strategy essentially compares the change in outcome of individuals before and after they turn 55. Because the withdrawal age is birth-month specific, we can include a full set of year-month fixed effects $\left(\delta_{t}\right)$ to control for seasonal variation in consumption expenditures as well as the average of all other concurrent aggregate factors. The individual fixed effects $\left(\alpha_{i}\right)$ control for time-invariant differences in consumption preferences at the individual level.

Following Agarwal et al. (2007), the results can be interpreted as an event study. The coefficient $\beta_{0}$ measures the immediate dollar response to reaching the withdrawal age of 55 , relative to observations in at least four months before turning 55. The coefficients $\beta_{1}, \ldots, \beta_{12}$ capture the change in outcome in each of the twelve months after the individual turns 55. The coefficients $\gamma_{s}$ for $s=1,2,3$ capture the change in the outcome (bank account balance, credit/debit spending, debt) in each of the three months prior to when an individual turns 55 . These coefficients capture any pre-withdrawal-age trends in bank account balances or anticipatory effects in spending or debt response. Comparing the magnitude and significance of the $\beta$ 's and $\gamma$ 's can inform us about the validity of our experiment and whether an individual is smoothing income. Since spending is a flow variable, the cumulative coefficient $b_{s}=\sum_{t=0}^{s} \beta_{t}$ measures the cumulative change in spending after $s$ months, for $s=0-12$, starting from the month when they turn $55(t=0)$.

If the exact month in which individuals turn 55 in our sample is approximately random, ${ }^{23}$ we would not expect a significant increase in bank account balances in the months just prior to the withdrawal age. For debit and credit card spending, our test of whether an individual is smoothing income would amount to testing whether the $\beta$ 's are significantly different from the $\gamma$ 's. If individuals are smoothing consumption, we should expect that the estimates $\left(\gamma^{\prime} s\right.$ and $\left.\beta^{\prime} s\right)$ are not statistically significantly different from one another. If the $\beta^{\prime} s$ are significantly different from the $\gamma^{\prime} s$, this would imply that individuals are not smoothing their income and are responding to the anticipated increase in liquidity through access to CPF balances. For debt response, if individuals are smoothing consumption, we might expect that in the run-up to the

\footnotetext{
${ }^{23}$ We show in Figure A1 in the Appendix that the calendar months in which Singaporeans turned 55 in our sample period are evenly distributed. Recall also from Figure 1 that all major demographics (e.g., gender, marital status, proportion of Chinese) are smooth functions around age 55.
} 
withdrawal age, individuals may start to increase their debt (by borrowing against future expected income) and would systematically decrease their debt as they reach 55 and beyond.

\section{Results}

\subsection{Average Response of Account Balances, Spending and Debt}

We begin by examining the average change in account balance, spending and debt as an individual reaches the CPF withdrawal age of 55. Table 1 reports the estimates from Equation (1) which capture the monthly change in each of the outcomes for individuals three months prior to turning $55(\gamma)$ and individuals zero to 12 months after turning $55(\beta)$, relative to the individuals' outcomes four months and earlier prior to turning 55 (omitted group). All the specifications include individual fixed effects to capture time-invariant sources of unobserved heterogeneity across individuals and year-month fixed effects to capture aggregate and seasonal patterns in consumption and spending. The estimates in column (1) indicate that individuals in our sample experience a large and statistically significant increase of $\$ 12,571$ in account balances on average in the year after turning 55 relative to four months and earlier prior to turning 55 . The estimate in the first row of column (1) indicates that this increase in account balance only takes effect after the individual turns 55 - in the three months prior to turning 55, there is no significant change in the account balance (the coefficient estimate is $\$ 872.1$, with a t-statistic of 0.99). These results strongly indicate that the increase in balances only occur after an individual reaches the withdrawal age, and that account balances are stable in the six months prior to age 55. The magnitude of the response is roughly in line with reported withdrawal amount published on the official website $(\$ 11,000)$.

\section{[Insert Table 1 about Here]}

Columns (2) to (4) examine the effects of reaching the withdrawal age on total spending (credit plus debit), credit spending and debit spending, respectively. The estimates in column (2) indicate that in the three months prior to consumers' turning age 55, their total monthly card spending rises, albeit very modestly, by $\$ 55$, relative to four months or earlier prior to turning age 55. After consumers turn 55, total card spending rises by an additional $\$ 41$. Columns (3) and (4) indicate that in the three months prior to turning 55, both monthly debit and credit spending rise by similar amounts ( $\$ 20-\$ 30)$, while the increase in total spending after turning 55 is mostly concentrated in debit card spending. Column (5) examines the debt response. There is little change in debt in the three months prior to turning 55; however, consumers begin to pay down credit card debt after they reach the withdrawal age, with individuals reducing their average debt by a statistically significant $\$ 210 .^{24}$

\footnotetext{
${ }^{24}$ This finding is consistent with Agarwal et al. 2007 and Agarwal and Qian (2014).
} 
In sum, we find that upon reaching the withdrawal age of 55, consumers do withdraw a significant portion of their CPF cash balances and bank the money into their bank accounts. We find modest evidence of increased spending both just prior to, and after turning 55. The magnitude of the (cumulative) spending effects is small and constitutes a relatively small fraction (approximately 9 percent) of the rise in account balances. We also find that consumers begin to pay down debt after reaching the withdrawal age. It is worth noting that the change in monthly bank account balance reflects the income inflow net of outflows such as consumer spending using cash and checks. This has two implications. First, the observed account balance increase could be a lower bound of the withdrawal amount. Second and more importantly, we can infer that spending response through cash and checks should be minimal (if any) since our estimated account balance increase is similar to the back-of-the-envelope calculation based on the median statistics published by CPF. In other words, the small spending effects (through debit and credit cards) are unlikely to be due to mismeasurement of the complete consumption activity of these individuals.

To understand the consumption response after the anticipated increase in disposable income, another informative exercise would be to estimate the MPC after individuals turn 55. However, we do not observe, at the individual level, the withdrawal amount, making this exercise difficult. We also investigate an additional benefit out of such a large increase in disposable income. The extra liquidity from the pension saving withdrawal potentially facilitates better consumption smoothing, resulting in lower consumption volatility. For each individual in our sample, we compute the standard deviation (and the high minus low range) of monthly total card spending during the pre-55 period and the post-55 period respectively (see Table A2 for details). There is some evidence that the variability in spending falls during the one year post-55 period, but the results are statistically weak and are at best suggestive. The weak results imply that even the consumption smoothing motive as predicted by theory cannot explain away such large withdrawal decision from the CPF at age 55.

\subsection{Response Dynamics}

To further sharpen the results in Table 1, we examine the average monthly response of account balance, spending and debt to the reaching of the withdrawal age. We investigate the dynamic evolution of the responses over a sixteen-month period, beginning in the three months prior to turning 55 and following individuals for up to 12 months after they turn 55 . Table 2 reports the marginal coefficients from the estimation of Equation (2). The magnitude of the coefficients should be interpreted relative to when individuals were at least four months prior to turning 55 (omitted group). Figure 2 graphs the entire path of the (estimated) response dynamics, along with the corresponding 95 percent confidence intervals. The results can be interpreted as an event study, with month zero being the time when an individual turns 55 in event time.

[Insert Figure 2 about Here] 
Column (1) of Table 2 reports the point estimates for account balances. In the three months prior to an individual turning 55, we find little change in monthly account balances. This reinforces the exogeneity of pension withdrawal eligibility, and corresponding disposable income shock, induced by the CPF withdrawal age rule. On an individual's $55^{\text {th }}$ birthday (at $s=0$ ), we find that account balances increase by $\$ 8,796$. One month later, account balances rise further, and are now about $\$ 15,000$ higher than before the withdrawal age. Starting from the second month after turning 55, the account balance starts to decline gradually, plateauing at about 9,000 to 10,000 six months after turning $55 .{ }^{25}$ The estimated account balance increase is remarkably similar in magnitude and pattern to the difference in the unconditional means of the account balance in Figure 2 among individuals just a few months older or younger than 55 . This further reinforces the random nature of our age treatment.

[Insert Table 2 about Here]

Column (2) shows the evolution of the spending response. In the two to three months prior to individuals' turning 55, their credit and debit card spending is not significantly different from that at least four months prior to their turning 55. Total monthly spending picks up in the month before turning 55 , increasing by a statistically significant $\$ 43$. Monthly spending increases by about $\$ 105$ on reaching 55 and $\$ 118$ one month after turning 55. Total spending continues to increase for about three months after turning 55 before gradually declining. The cumulative spending response up to three months after turning 55 is approximately $\$ 429$. Most of this increase in spending is driven by an increase in debit card spending, with little or no significant change in credit card spending (columns (3) and (4)). Although most of the response coefficients for total spending are significant, at least in the few months after turning 55, note that the magnitude of the spending response is small relative to the change in account balances. In column (5), we observe that in the months prior to turning 55, consumers have monthly credit card debt that remains stable. However, upon reaching the withdrawal age, consumers begin to pay down debt, decreasing their debt at 55 by about $\$ 116$. Over the next twelve months, credit card debt remains $\$ 300$ to $\$ 500$ lower.

Taken together, the results in Table 2 and Figure 2 indicate that in response to the CPF withdrawal age, consumers withdrew their pension funds almost immediately and, on average, monthly account balances remained $\$ 10,000$ higher one year after the withdrawal age. Interestingly, the average consumer did not appear to use the withdrawn funds to increase spending substantially. Most of the spending changes were concentrated among low-liquidity consumers and took place through the use of debit cards. Consumers also used the extra liquidity to decrease their credit card debt. Overall, the magnitude of the response appears largely

\footnotetext{
${ }^{25}$ Individuals that do not withdraw their CPF at 55 may apply to do so anytime. Individuals who had previously withdrawn their CPF upon reaching 55 will be eligible to withdraw yearly, on or after their birthday. Some individuals may apply for another withdrawal within their birthday year if they have been unemployed or if they are self-employed and have not been continuously working or receiving income in any business or trade for six months before the date of the CPF withdrawal application.
} 
consistent with the predictions of the LCPIH with consumers using a small part of the increase in liquidity to pay down their credit card debt and to fund a modest increase in spending. This finding is similar to that in Beshears et al. (2008) who suggest that access to pension savings (in the form of 401(k) loans) may allow for consumption smoothing particularly among liquidityconstrained consumers and has a small effect on the total wealth accumulation of the elderly.

\subsection{Magnitude Hypothesis}

Our results are in sharp contrast to the findings in Agarwal and Qian (2014) who use the same dataset to study the impact of spending and debt responses to an unanticipated one-time government cash payout of US\$78 to US\$702. In that study, they find evidence of a large and significant spending response, with consumers increasing their spending by 90 cents for every dollar received. The difference in our findings is likely to be due to the size of the income shock examined with the same households being substantially more responsive to a small shock relative to a large shock in disposable income. For example, findings in Hsieh (2003) and Scholnick (2013) suggest that the magnitude of the income shock is critical in understanding consumers' responses to changes in disposable income.

To directly test the hypothesis, we study the consumption response of the individuals in our sample-those who reach 55 during our sample period-to the Growth Dividend program studied in Agarwal and Qian (2014). We follow the empirical specification in that paper and perform a difference-in-differences analysis. The treated group is composed of Singaporeans who turn 55 during our sample period (i.e., the focus of our current study). These individuals are also entitled to the Growth Dividend payout in 2011, and the amount of the positive income windfall depends on their 2010 income and assessed value of their residence property. The control group corresponds to the matched foreigners based on the nearest neighbor propensity score matching methodology. Please refer to Agarwal and Qian (2014) for details on the income shock and the empirical methodology.

We report the average consumption (and debt) response to the Growth Dividend program in Table 3. During the 10-month post-announcement period, the treatment group has experienced a significant increase in their total card spending, driven more by their debit card use. On average, Singaporeans who reach 55 in our sample period spent 11 cents per month for each dollar received, or equivalently $\$ 1.1$ dollars cumulatively for each dollar received. ${ }^{26}$ The spending effect is both statistically and economically significant, compared to an MPC estimate of 80 cents spent out of one dollar received in the full sample (Agarwal and Qian, 2014). Combined with Tables 1 and 2, results in this section provide strong evidence, by comparing within-person

\footnotetext{
${ }^{26}$ We also follow Agarwal and Qian (2014) and verify that there is no spending response using other payment instruments such as cash and checks, by using the number of banking transactions and the implied cash and check spending from the change in the monthly bank account balances.
} 
responses to income shocks of different amounts, that the magnitude of the income shock is an important factor in understanding consumption response to disposable income shocks.

[Insert Table 3 about Here]

\subsection{Heterogeneity in Response across Consumers}

Next, we examine whether different consumers had heterogeneous responses to the access to pension savings induced by the CPF withdrawal age policy. Previous literature has documented that liquidity consumers may respond more strongly to positive disposable income shocks (e.g. Agarwal et al. 2007). We use three different proxies for liquidity constraints in our data based on an individual's credit limit with the bank, reported monthly income and their pre-period bank account balance.

To estimate the response dynamics of the effect of access to CPF savings on withdrawals, consumption and debt of consumers with low vs. high liquidity, we estimate the following dynamic specification:

$$
\begin{aligned}
Y_{i, t}=\delta_{t}+\alpha_{i} & +\sum_{s=1}^{3} \gamma_{s} W_{i, t+s}+\sum_{s=1}^{3} \phi_{s(N-1)} W_{i, t+s} \times 1_{N-1} \\
& +\sum_{s=0}^{12} \beta_{s} W_{i, t-s}+\sum_{s=0}^{12} \theta_{s(N-1)} W_{i, t-s} \times 1_{N-1}+\epsilon_{i, t}
\end{aligned}
$$

where $\mathrm{N}$ is the number of subgroups of consumers that we decompose into. To save space, we do not report the marginal effect coefficients. ${ }^{27}$ Instead, we plot the response coefficients, along with 95 percent confidence intervals (Figure 3).

[Insert Figure 3 about Here]

\section{A. Low Credit Limit vs. High Credit Limit}

We classify consumers in our sample as having a low credit limit if their maximum credit card limit in the first three months in our sample period (2010:04-2010:06). In studying the heterogeneous response in this section, we exclude these months from our analysis. We also remove Singaporeans who turn 55 during these three months. Consumers have a high (low) credit card limit if their maximum credit card limit during the pre-sample period is in the top, or SGD 10,000 (bottom, or SGD 6,000) tercile of the distribution.

Panel A of Figure 3 shows the comparison in the path of account balances, total spending and debt for these two groups of consumers. Similar to the patterns observed in Figure 2, there is a sharp spike in account balances for both low- and high-credit consumers on reaching the

\footnotetext{
${ }^{27}$ The results are available on request.
} 
withdrawal age. High-credit-limit consumers experience a larger spike in account balance (approx. \$18,000) relative to low-credit-limit consumers (approx. \$12,000) one month after turning 55. The difference in magnitude is likely to reflect the fact that high-credit-limit consumers are likely to have a larger CPF cash balance available for withdrawal. In the months after turning 55, the account balance of low-credit consumers decline gradually by about 40-50 percent. Account balances of high-credit-limit consumers decline to about $\$ 14,000$ in the twelve months after turning 55 . These findings indicate that both groups of consumers respond strongly to pension savings access by withdrawing their eligible pension funds and that a large portion of their withdrawn pension savings are maintained in the low-interest-yielding bank account up to one year after turning 55 .

Turning to the cumulative spending response, we observe that for high-credit-limit consumers, total spending begins to increase in the three months prior to their turning 55 and continues to increase gradually over time, plateauing at about $\$ 500$ four months after they turn 55 . While the large standard errors make it difficult to reject that these patterns are significantly different from zero, the upper confidence bound indicates that cumulative spending over the 15-month period is unlikely to exceed $\$ 2000$. This implies that even under conservative assumptions, relative to the large increase in bank account balances, the spending response of high-credit-limit consumers is rather small, with the spending increase comprising no more than 3 percent (using total spending of \$500) to 11 percent (using total spending of \$2000) of the total increase in account balances in the months after turning 55 .

For low-credit-limit consumers, total spending appears to only begin increasing in the month just prior to their turning 55. Relative to the high-credit-limit group, the increase in cumulative spending over time is much larger, with cumulative total spending about $\$ 1000$ higher over the 15-month period. Consistent with the predictions from the LCPIH with liquidity constraints, it appears that low-credit-limit consumers increase their spending more in response to the predictable increase in liquidity induced by access to pension savings. Nevertheless, the spending response comprises no more than 8 percent (using total spending of \$1000) to 19 percent (using the upper confidence bound of total spending of \$2250) of the total increase in account balances in the months after turning 55.

Both groups of consumers use their access to pension savings to pay down their credit card debt. Similar to that observed in Figure 2, in the months just prior to turning 55, there is no significant change in credit card debt for both groups of consumers. Upon reaching the withdrawal age, credit card debt for both groups of consumers fall significantly and is about $\$ 300-\$ 400$ lower for low-credit consumers and $\$ 600$ lower for high-credit limit consumers at the end of the sample period.

B. Low Monthly Income vs. High Monthly Income 
Our second proxy for liquidity constraints is based on monthly income during the pre-sample period- low-income consumers are those whose average pre-sample-period monthly income is in the bottom tercile of the distribution (or SGD 3,471). High-income consumers are those with an average pre-sample monthly income in the top tercile of the distribution (or SGD 5,812).

Panel B of Figure 3 shows the comparison in the path of account balances, total spending and debt for these two groups of consumers. Similar to the patterns in Panel A, bank account balances rise by a statistically significant $\$ 10,500$ for low-income consumers and gradually decline by about 50 percent to approximately $\$ 5,200$ twelve months after age 55 . High-income consumers experience a significantly larger increase in bank account balances of about $\$ 20,000$ in the month after turning 55. This balance declines somewhat in the three months after consumers turn 55 before remaining relatively stable at about $\$ 16,000$. Therefore, both groups of consumers respond to the access in pension savings by withdrawing a portion of their eligible funds and maintaining a sizeable fraction of it in their bank account balance.

In terms of spending, low-income consumers respond to the increase in liquidity by gradually increasing total spending starting about a month before turning 55. Cumulative total spending is about $\$ 1000$ higher in the twelve months after turning 55. In contrast, the average increase in cumulative spending is small (and statistically insignificant) for high-income consumers. Using the upper confidence bound on total cumulative spending for both groups, we can reject total spending increases in excess of $\$ 2500$ for low-income consumers and $\$ 1500$ for high-income consumers. These results are consistent with the spending patterns of low-liquidity consumers being more responsive to disposable income shocks relative to high-liquidity consumers. Finally, both groups of consumers use the increase in disposable income to pay down credit card debtcredit card debt is significantly lower by about $\$ 500$ for both high-income and low-income consumers.

\section{Low Bank Account Balance vs. High Bank Account Balance}

Third, consumers are classified as having a low bank account balance if their average presample-period monthly bank account balance is in the bottom tercile of the distribution (or SGD 6,838). Consumers are classified as having a high bank account balance if their average monthly balance in that period is in the top tercile of the distribution (or SGD 35,810). Panel C shows that both groups of consumers experience a sharp increase in their bank account balances upon turning 55. In contrast to the two other proxies for liquidity constraints, the magnitude of the increase (approx. \$14,000) is similar for both groups of consumers one month after reaching the withdrawal age. Nevertheless, while we observe a reduction of about 45 percent in account balances for low-balance consumers after 12 months, account balances remain largely stable for high-balance consumers. Total cumulative spending increases sharply for low-balance consumers on turning 55 and are significantly higher at \$2500 one year later. In contrast, we do not observe any evidence of an increase in cumulative spending for high-balance consumers (in 
fact, average cumulative spending appears to decline over the sample time period; however, the standard error bands are large). The total reduction in credit card debt at the end of the 12 months is significantly larger (t-stat of the F-test is 2.33) for low-balance individuals (\$808) relative to high-balance individuals (\$356).

\subsection{Heterogeneity Analysis by Demographics and Robustness}

\section{$\underline{\text { A. By Demographics }}$}

In Panels A-C of Appendix Figure A2, we investigate the heterogeneous responses along key demographic dimensions such as gender, ethnicity, and marital status. Across the different demographic groups, the main results remain robust - there is a significant increase in account balance, which cannot be explained by an increase in total spending and the reduction in credit card debt.

In Panel D, we show that the different withdrawal caps in 2010, 2011, and 2012 do not affect our results. We study the dynamic responses separately by the year individuals turned 55 in 2010 and 2011. ${ }^{28}$ Recall that in 2010, individuals were eligible to withdraw 30 percent of their CPF balances. In 2011, individuals were only eligible to withdraw 20 percent of their CPF balances. The main results are qualitatively similar, although the spending and debt responses are more muted in the sample of individuals who turned 55 in 2011.

In addition, we address the concern of a potentially muted spending response for individuals with joint bank accounts, because the spending response of the joint holders (e.g., spouse or children) is not captured. Our previous sample splits by marital status alleviate this concern as we find a similar pattern in the bank account balance, spending and credit card debt response among the married and single individuals who are turning 55. In Panel D, we exploit the information on whether the individuals have joint bank accounts to further study this possibility. We indeed observe a stronger (total card) spending response among individuals without a joint bank account, suggesting that the spending response among those with joint bank accounts may be underestimated. However, the spending response during the 12 months post-55 among those without joint bank accounts is still small relative to the bank account increase, which stays significantly positive during the post-55 12-month period.

\section{B. Response during the 24-month post-55 Window}

We also study the persistence of the response in the extended 24-month period after individuals turn 55. Figure A3 shows that the spending and credit card debt responses are persistent up to two years after individuals turn 55. Bank account balance remains high and there appears to be another increase in the balance in the second year (months 18 and 19) after individuals turn 55. However, the magnitude is small relative to the increase during the first two months after the $55^{\text {th }}$

\footnotetext{
${ }^{28}$ We are not able to look separately at individuals who turned 55 in 2012 due to the small sample size.
} 
birth month. This suggests that the most significant withdrawal occurs immediately when the option becomes available. $^{29}$

\section{Spending Responses by Different Categories}

Next, to understand the spending response better, we group the total card spending into eight major categories according to the merchant description provided. These spending categories include supermarket, service, dining, entertainment, apparel, travel, small durable goods, and online. Appendix Table A1 presents the results estimating Equation (1) for each of the eight categories. We find that spending responds most strongly in the discretionary as well as small durables category, consistent with the literature (Parker et. al. 2013). There appears to have been some consumption smoothing, as reflected by significant spending response during the threemonth period before individuals turned 55. However, the smoothing is partial since the spending response is larger in the post-period than in the pre-period. This is especially true for small durable goods, where the difference is statistically significant at the 10 percent level.

\section{Falsification Tests}

We conduct a series of falsification tests to show that the increase in disposable income at age 55 is the result of the age-specific CPF withdrawal policy rather than other unobserved changes that may occur at age 55. While our dynamic specification provides strong evidence that bank account balances are stable in the months prior to turning age 55, one may be concerned that there are other unobserved changes affecting consumers at age 55.

To address this possibility, we examine the responses of account balances, spending and debt among foreign consumers. Since foreigners are not subject to the CPF policy, we should not observe any changes in their account balances, spending or debt patterns around age 55. Individuals are classified as foreigners based on nationality. Since non-Singaporeans could also be permanent residents (who are also subject to the CPF policy), we remove ethnic Chinese, Indians, and Malays from the sample of foreigners. ${ }^{30}$ Panel A of Table 4 reports the estimates of Equation (1) on the foreigners in our sample. Consistent with our hypothesis, we do not find any

\footnotetext{
${ }^{29}$ We focus our main analysis on the 12-month window after individuals turn 55 . This is because of our short time series in the panel data: we only observe the $13^{\text {th }}$ month after the $55^{\text {th }}$ birth month for less than half of the treated individuals in the dataset, and information on the $24^{\text {th }}$ month after the $55^{\text {th }}$ birth month is available for around 100 individuals in our sample. This makes the point estimates for the later event months very noisy and less reliable (as can be seen from the wide confidence interval shown in Figure A3).

${ }^{30}$ It is possible that the sample still includes permanent residents who are non-Chinese, non-Indian, or non-Malay. These individuals would also be subject to the CPF policy - this would tend to reveal an effect at age 55. Nevertheless, we expect that most of the non-Chinese/Indian/Malay foreigners in our sample are not Singaporeans/PRs. 80\% of permanent residents in Singapore are Chinese or Indian nationals (Please refer to Table 1 in the Census of Population 2010 for the detailed statistics

(http://www.singstat.gov.sg/publications/publications and_papers/cop2010/census_2010_release1/cop2010sr1.pdf), and only 3.3\% of Singapore citizens and PRs were non-Chinese/Indian/Malay in 2012 (Department of Statistics, Singapore).
} 
evidence of significant changes in the account balance, spending patterns or debt for the sample of foreigners. ${ }^{31}$

\section{[Insert Table 4 About Here]}

Next, we address the possibility that there may be other treatments for the same set of individuals at the age cut-off. For example, there is also a discrete change in the employer and employee contribution rate at several age cut-offs (including 50, 55, and 60; see section C in the Appendix for details). First, we note that the contribution rate changes at age 55 have two offsetting effects: while they increase the disposable income (by requiring employees to contribute less pre-tax salary to CPF), they also decrease the wealth level in the form of smaller pension contributions from the employers. A priori, it is not clear how consumption should respond. Furthermore, we perform a falsification test among Singaporeans at age 50 who are subject to similar CPF contribution rate changes but do not yet have the CPF withdrawal option. Panel B of Table 4 reports the estimates of Equation (1) on the sample of Singaporeans in the months just before and after individuals turn 50. Reassuringly, we find little change in the outcome variables - all the coefficients for account balance, spending, and debt are small and not statistically significant at conventional levels. This provides further evidence that the patterns of consumer behavior are virtually stable in the absence of the CPF withdrawal policy, reinforcing our conclusion that the dynamic responses that we observe around age 55 are indeed the causal response to the CPF withdrawal policy.

Overall, our results suggest that individuals respond to the CPF withdrawal policy by choosing to withdraw a significant amount from their pension savings account immediately upon reaching age 55. On average, the magnitude of the cumulative spending response is quite small, around 7 percent at the end of the 16-month window (from month -3 to month 12). We find that this increase in spending is concentrated in debit card spending and among more liquidityconstrained consumers, consistent with the hypothesis that liquidity-constrained consumers are likely to respond more strongly to positive income shocks. For high-liquidity consumers, we find virtually no evidence that spending responds to the large change in disposable income. Consistent with theoretical predictions, we find that consumers use the increase in disposable income to pay down credit card debt. Overall, consumer behavior appears to largely conform to the predictions of the life-cycle/permanent income hypothesis.

These findings shed new light on the savings and consumption decision for the aging population, especially those approaching retirement. Consistent with Beshears et al. (2008), we find that giving consumers access to their pension savings increase liquidity and allow for consumption smoothing especially among liquidity-constrained consumers. Furthermore, the option to

\footnotetext{
${ }^{31}$ For both falsification tests, we also follow Figure 1 and plot the key variables of interest in the cross section around the "treatment" thresholds (Figure A4 and A5 in the Appendix). Consistently, we do not find a jump in the account balance, spending and debt around the threshold.
} 
withdraw pension savings does not appear to lead to overspending in the present at the expense of future retirement security.

\subsection{Who Withdrew their Pension Savings?}

One salient finding in Section 5.2 lies in a significant portion of the withdrawn funds having remained in individuals' bank account balances up to one year after withdrawal. This is consistent with the survey response, mentioned earlier in the introduction, that people do not intend to spend (much of) the withdrawn funds. Rather, they indicate their plans to save the funds through various investment instruments (e.g., bank, stocks, bonds, and property). Nevertheless, this is a puzzling finding. If consumers withdraw out of their demand for investment flexibility, the question arises of why they chose to withdraw their pension funds immediately upon eligibility and to leave these funds sitting in a low-interest-bearing bank account (less than 0.1 percent) at the expense of a 2.5 percent- 4 percent guaranteed interest rate offered on their retirement account by the CPF. Particularly for high-liquidity consumers, if they do not invest the withdrawn funds somewhere else, the dominant strategy would have been to withdraw the excess funds in their bank account one year after eligibility, as they would still be entitled to withdraw the same funds on their $56^{\text {th }}$ birthday.

One reason why individuals choose to withdraw their CPF cash balances on turning 55 rather than to leave their money in higher interest yielding CPF accounts may be government policy regarding the treatment of CPF funds. However, the CPF withdrawal rule is specific and fixed within the same birth cohort. This means that even if the policy changes in the future, the same cohort turning 55 in year 2010 is always eligible to withdraw 30 percent of the available CPF balances, whether they decide to make the first withdrawal at age 55 (i.e., in year 2010) or at age 56 or later (i.e., in year 2011 or later).

Alternatively, consumers have an incentive to withdraw and deposit in a liquid bank account despite the lower savings rate due to the restricted withdrawal option. Although individuals who do not withdraw their full entitlement are eligible to withdraw it in the future, they are only allowed to do so once a year, on their next birthday. This restricted access to funds is likely to increase transaction costs, especially for individuals with high liquidity needs (e.g., for emergency expenses). ${ }^{32}$ However, these concerns are unlikely to explain away the withdrawal decision for the following reasons. First, it is fairly convenient and efficient to withdraw the CPF savings: the application is easy and the processing takes no more than 10 working days. Therefore, it is hard to rationalize the decision to immediately exercise the withdrawal option upon turning 55 with little use of the money; a clearly better alternative is to keep the savings in the CPF earning a higher interest rate until the need (to either spend or invest) arises. Second,

\footnotetext{
${ }^{32}$ Previous literature has pointed out that households may choose to hold low-interest checking balances in addition to high-interest credit card debt and other alternative investment savings, because these demand deposits, credit cards and other forms of investment savings are not perfect substitutes and generally differ in transaction utility (Lehnart and Maki, 2002; Gross and Souleles 2002)
} 
even for individuals with potentially higher liquidity needs, it is not obvious that withdrawing cash from the CPF is the only option, since their CPF savings are partially liquid. Individuals can still tap the withdrawn funds in the Ordinary Account for investment and housing expenses and use the unwithdrawn funds in the Medisave Account for healthcare expenses. Even though there is a rich menu of investment choices for CPF members (Koh, et al., 2008; Koh and Mitchell, 2010), Koh, et al. (2007) show that most CPF members do not use the external investment vehicles since the default interest rates in the OA and SA account (2.5 percent-4 percent) are attractive and thus present a high investment hurdle for other investment choices. Third, the transaction costs and demand for liquidity may be more important for the liquidity-constrained consumers; however, we observe an equally strong pattern in withdrawal upon turning 55 among individuals with higher wealth level and credit market access.

Taken together, this may seem as though the aging households in our sample are making savings and investment mistakes by failing to exploit arbitrage opportunities (Gross and Souleles, 2002 and Choi, Laibson and Madrian, 2011). To investigate this issue further, we study the determinants of the withdrawal decision of eligible individuals in our sample. To characterize the decision to withdraw, we first compute the average change in the monthly bank account balance during the period before eligible individuals turned 55. In the distribution, 50 percent of qualifying individuals have an average monthly change in balance of smaller than \$20, 75 percent of qualifying individuals have an average monthly change in balance smaller than $\$ 679$, and 90 percent of such individuals have an average change in balance smaller than \$2867. By contrast, 55 percent (42 percent) of them experienced a balance increase in the month they turned 55 that is greater than 679 (2867). Consistent with previous findings, this suggests that a large portion of eligible individuals withdrew funds from their pension savings.

Which individuals withdrew their pension savings upon turning 55? To shed some light on this question, we study how individual characteristics are associated with the decision to withdraw pension savings in a series of OLS regressions. ${ }^{33}$ The dependent variable is a dummy variable equal to one if the change in bank account balance in the month Singaporeans turned 55 is greater than the $75^{\text {th }}$ percentile in the distribution of the average monthly change in balance in the pre-55 period among these individuals. The assumption is that individuals withdraw from pension savings if the change in their bank account balance in the month they turned 55 is greater than the change in account balances of the $75^{\text {th }}$ percentile in the pre-55 distribution.

The first column in Table 5 relates our measure of pension savings withdrawal to various financial variables such as pre-55 income, bank account balance, and credit card debt. Consistent with a liquidity-constraint interpretation, we find that individuals with a high level of pre-55 credit card debt are more likely to withdraw their pension savings. However, having a high bank account balance before turning 55 is also positively associated with the propensity to withdraw

\footnotetext{
33 The results are not sensitive to the OLS specification. As a robustness check, we replicate our analysis using
} logistic regression and the results remain the same. 
from pension savings, which is puzzling given that these individuals should be less liquidity constrained. We study demographics and other financial literacy indicators in the second column. Malay Singaporeans are more likely to withdraw from pension savings, compared to Chinese Singaporeans or Indian Singaporeans. More interestingly, conditional on the financial variables, having more banking experience or privileged access to banking service and financial counseling is associated with a significantly smaller likelihood of withdrawal (Column 3, Table 5). ${ }^{34} \mathrm{We}$ also use the $90^{\text {th }}$ percentile of the pre- 55 monthly change in account balance as an alternative dependent variable to proxy for individuals who choose to withdraw their pension savings, and the results are very similar (Columns 4-6, Table 5). Although there is a role of liquidity constraints (and potential demand for investment flexibility) for the withdrawal decision, consumers' demographics, especially those related to their financial literacy and sophistication appear to be important determinants of consumers' withdrawal decisions.

\section{[Insert Table 5 About Here]}

\section{Conclusion}

This paper exploits an administrative regulation in Singapore that allows individuals to cash out a fraction of their pension savings at age 55, in combination with a unique panel dataset of 180,000 consumer financial transactions, to identify the causal effect of the access to pension savings on consumers' withdrawal, consumption, and savings decisions. During our sample time period from April 2010 to March 2012, individuals were entitled to withdraw 10 percent to 30 percent of their pension savings. Publicly released aggregate statistics show that close to SG\$3 billion pension savings are withdrawn each year, which amount to about 1 percent of 2011 GDP in Singapore. Withdrawing individuals on average cash out SG\$11,000 per person, almost triple the average monthly salary in the population in our sample period.

Our findings are summarized as follows. We find that, on average, as individuals became eligible to cash out a fraction of their pension savings, their bank balances rose by about $\$ 15,000$ one month after turning 55. Cumulative spending rose by about $\$ 600$ twelve months after turning 55. Most of the spending response was driven by an increase in debit card spending and increased spending of low-liquidity consumers. We find little evidence that high-liquidity consumers changed their spending patterns in response to the increase in disposable income. Both groups of consumers used the increase in disposable income to draw down credit card debt - on average, debt was about $\$ 500$ lower in the twelve months after an individual turned 55. On average, bank account balances declined by about one third after twelve months, with the balance remaining significantly higher $(\$ 10,000)$ even at the end of our sample period.

\footnotetext{
${ }^{34}$ Instead of using the continuous measure of individual wealth indicators (as seen in Table 4), we also create, as controls, dummy variables for individuals with high bank account balance (e.g., in the top decile or above some arbitrary thresholds) to capture the non-linearity in the wealth variables. We still find that access to banking service and financial counseling has incremental power in explaining the withdrawal decision.
} 
Our main contribution, in relation to prior literature, is three-fold. First, we are able to cleanly identify the causal effect of access to pension savings on the decision to withdraw and the effect on individuals' consumption and savings. This provides us important inputs for understanding how near-retirement consumers make financial decisions when faced with the early access option to their pension savings and the associated predictable increase in disposable income. While we document that liquidity-constrained consumers use these funds to smooth consumption, on average, consumers do not appear to spend the withdrawn savings. It implies that access to pension savings does not lead consumers to excessively increase current consumption at the expense of future financial security. This result is especially informative (and comforting) considering that there are no other social safety nets in Singapore and pension is a significant source of consumers' retirement savings. Moreover, our empirical results are also consistent with the "magnitude hypothesis" and suggest that the size of the disposable income shock is important in understanding the consumption response in LCPI models.

Second, we raise a potential puzzle - a large amount of the withdrawals remains to sit in individuals' bank accounts without being consumed or invested, which could suggest behaviordriven incentives in the saving decisions of these near-retirement individuals. Third, we contribute to the policy debate on the role of 401(k) loans and its effect on consumption and wealth accumulation at retirement. Although early access to pension savings may lead individuals to make sub-optimal savings decision, the major concern of consumer overspending with the withdrawn savings seems unwarranted: on the contrary, providing access to pension savings may allow liquidity-constrained consumers to better smooth consumption. 


\section{References}

Aaronson, Daniel, Sumit Agarwal, and Erik French, 2012, Spending and Debt Response to Minimum Wage Hikes, American Economic Review 102: 3111-39.

Agarwal, Sumit, Amit Bubna, and Molly Lipscomb, 2013, Timing to the Statement: Understanding Fluctuations in Consumer Credit Use, University of Virginia Working Paper.

Agarwal Sumit, Souphala Chomsisengphet, Teck Hua Ho, and Wenlan Qian, 2013, Cross Border Shopping: To Consumers Respond to Taxes or Prices? Working Paper, National University of Singapore

Agarwal, Sumit, John C. Driscoll, Xavier Gabaix and David Laibson, 2009, The Age of Reason: Financial Decisions over the Life Cycle and Implications for Regulation, Brookings Papers on Economic Activity.

Agarwal, Sumit, Chunlin Liu, and Nicholas Souleles. 2007. The Reaction of Consumption and Debt to Tax Rebates: Evidence from the Consumer Credit Data, Journal of Political Economy, 115: 986-1019.

Agarwal, Sumit and Leslie McGranahan, 2013, Consumption Response to State Sales Tax Holidays, Federal Reserve Bank of Chicago Working Paper.

Agarwal, Sumit and Wenlan Qian, 2014, Consumption and Debt Response to Unanticipated Income Shocks: Evidence from a Natural Experiment in Singapore, American Economic Review, 104(12):4205-4230.

Beshears, John, James J. Choi, Josh Hurwitz, David Laibson and Brigitte C. Madrian, 2015, Liquidity in Retirement Savings Systems: An International Comparison, forthcoming, American Economic Review

Beshears, John, James J. Choi, David Laibson and Brigitte C. Madrian, 2008, A Primer on 401(k) Loans, Working Paper.

Beshears, John, James J. Choi, David Laibson and Brigitte C. Madrian, 2011, The Availability and Utilization of 401(k) Loans, Working Paper.

Browning, Martin and Dolores Collado. 2001. The Response of Expenditures to Anticipated Income Changes: Panel Data Estimates, American Economic Review, 91: 681-692.

Carroll, C, 1992, The Buffer-Stock Theory of Saving: Some Macroeconomic Evidence, Brookings Papers on Economic Activity, 2: 61-156.

Choi J, D. Laibson, and B. Madrian, 2011. \$100 Bills on the Sidewalk: Suboptimal Investment in 401(k) Plans, Review of Economics and Statistics, 93:748-763. 
Fong, J.H.Y., O. Mitchell, and B.S.K. Koh, 2011, Longevity Risk Management in Singapore’s National Pension System, Journal of Risk and Insurance, 78: 961-981.

Gross, D., and N. Souleles, 2002, Do Liquidity Constraints and Interest Rates Matter for Consumer Behavior? Evidence from Credit Card Data, Quarterly Journal of Economics, 117: 149-85.

Hoynes, H. W. and D. L. McFadden. 1997. The impact of demographics on housing and non housing wealth in the United States, in Michael D. Hurd and Yashiro Naohiro, eds., The Economic Effects of Aging in the United States and Japan, Chicago: University of Chicago Press for NBER, 153-194.

Hsieh, Chang-Tai, 2003, Do Consumers React to Anticipated Income Changes? Evidence from the Alaska Permanent Fund, American Economic Review, 93: 397-405.

Jappelli, T., 1990, Who Is Credit Constrained in the U.S. Economy? Quarterly Journal of Economics, 105: 219-234.

Jappelli, Tullio and Luigi Pistaferri, 2010, The Consumption Response to Income Changes, Annual Review of Economics, 2: 479-506.

Lu, T., O. Mitchell, S.P. Utkus, and J.A. Young, 2014, Borrowing from the Future: 401(k) Plan Loans and Loan Defaults, Wharton working paper series.

Koh, B., O. S. Mitchell, T. Tanuwidjaja, and J. Fong, 2007, Investment Patterns in Singapore's CPF Central Provident Fund, Journal of Pension Economics and Finance, 7: 1-29.

Koh, B., O. Mitchell, and J. Fong, 2008, Cost Structures in Defined Contribution Systems: the Case of Singapore's Central Provident Fund, Pensions: An International Journal, 13 (1-2): 7-14.

Koh, B., and O. Mitchell, 2010, What's on the Menu? Included versus Excluded Investment Funds for Singapore's Central Provident Fund Investors, Pensions: An International Journal, 15: 276-286.

Parker, J. 1999. The Reaction of Household Consumption to Predictable Changes in Social Security Taxes, American Economic Review 89: 959-73.

Parker, J., N. Souleles, D. Johnson, and R. McClelland, 2013,Consumer Spending and the Economic Stimulus Payments of 2008, forthcoming, American Economic Review.

Poterba, J.M., 1988, Are Consumers Forward Looking? Evidence from Fiscal Experiments, American Economic Review, 78: 413-418.

Scholnick, Barry, 2013. Consumption Smoothing after the Final Mortgage Payment: Testing the Magnitude Hypothesis, Review of Economics and Statistics, 95: 1444-1449.

Shapiro, M.D., and J. Slemrod, 1995, Consumer Response to the Timing of Income: Evidence from a Change in Tax Withholding, American Economic Review 85: 274-83. 
Shapiro, M.D., and J. Slemrod, 2003a, Consumer Response to Tax Rebates, American Economic Review 93: 381-96.

Shapiro, M.D., and J. Slemrod, 2003b, Did the 2001 Tax Rebate Stimulate Spending? Evidence from Taxpayer Surveys, In Tax Policy and the Economy, edited by J. Poterba. Cambridge, MA: MIT Press.

Souleles, N.S., 1999, The Response of Household Consumption to Income Tax Refunds, American Economic Review 89: 947-58.

Souleles, N.S., 2000, College Tuition and Household Savings and Consumption, Journal of Public Economics 77 (2): 185-207.

Souleles, N.S., 2002, Consumer Response to the Reagan Tax Cuts, Journal of Public Economics 85: 99-120.

Stephens, M., 2003, 3rd of the Month: Do Social Security Recipients Smooth Consumption between Checks? American Economic Review 93: 406-22.

Stephens, M., 2005, The Consumption Response to Predictable Changes in Discretionary Income: Evidence from the Repayment of Vehicle Loans, Carnegie-Mellon University, Working Paper.

Stephens, M., 2006, Paycheck Receipt and the Timing of Consumption, The Economic Journal, $116: 680-701$.

Stephens, M., 2008, The Consumption Response to Predictable Changes in Discretionary Income: Evidence from the Repayment of Vehicle Loans, The Review of Economics and Statistics, 90: 241-52.

Stephens, M., and T. Unayama, 2011, The Consumption Response to Seasonal Income:

Evidence from Japanese Public Pension Benefits, American Economic Journal: Applied Economics, 3: 86-118.

Tan, Soo San, 2004, The Central Provident Fund: More Than Retirement, Ethos (a publication by the Singapore Civil Service College).

Whitehouse, E., 2007, Pensions Panorama, The World Bank, Washington, D.C. 


\section{Figure 1: Sample Statistics by Age}

\section{A. Bank account balance}

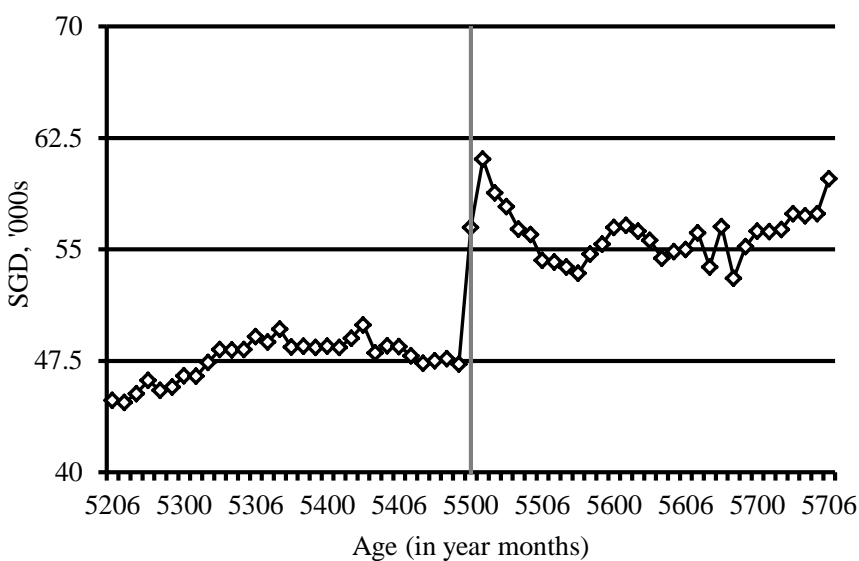

\section{Monthly credit card debt}

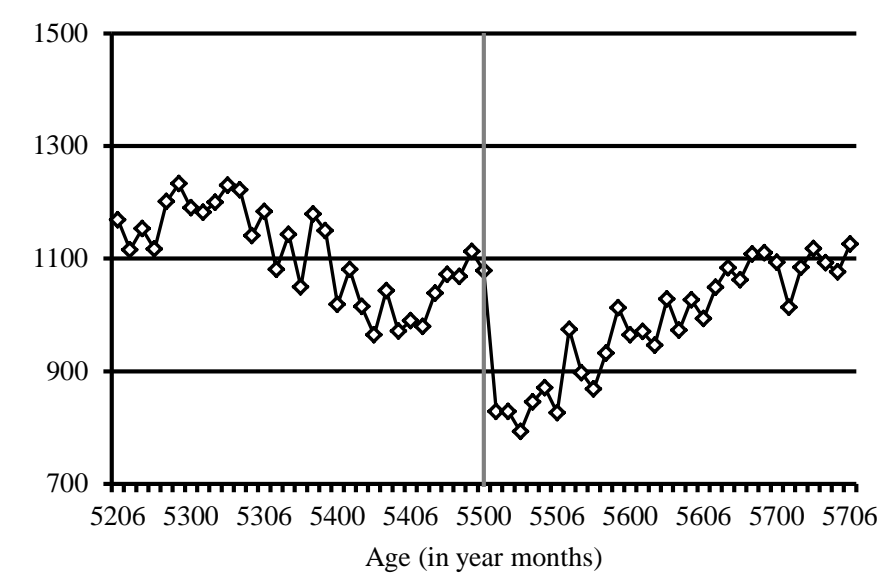

\section{B. Total spending (Debit + Credit Card)}

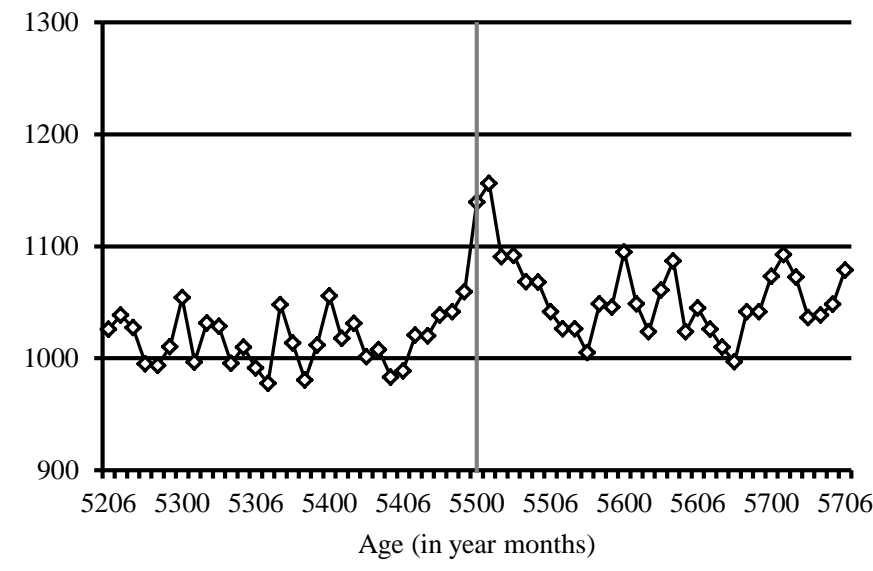

\section{Monthly income}

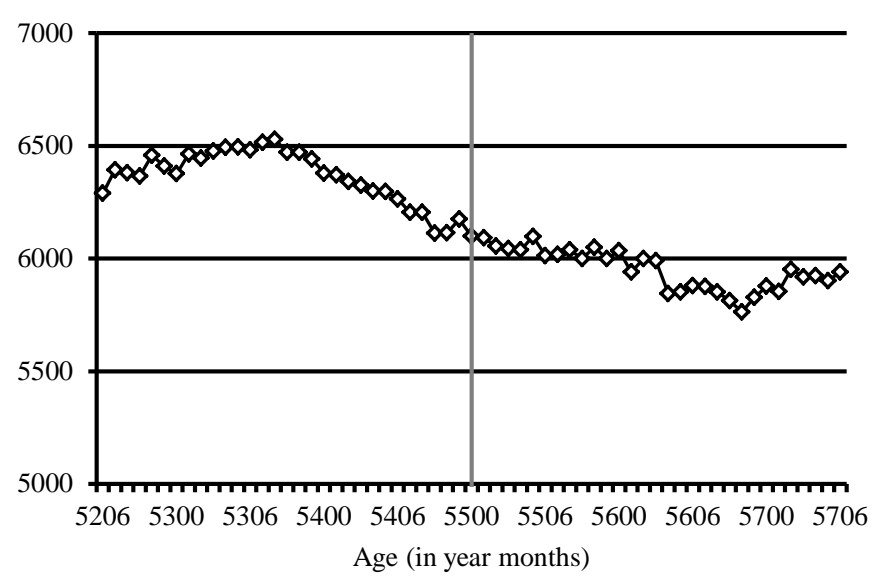

Note. Each panel plots the variable means by the age (in year-months). The sample includes all Singaporean individuals who turned 55 from April 2010 to March 2012. The vertical line indicates individuals in the sample who are age 55 and 0 months. 


\section{E. Gender (\% female)}

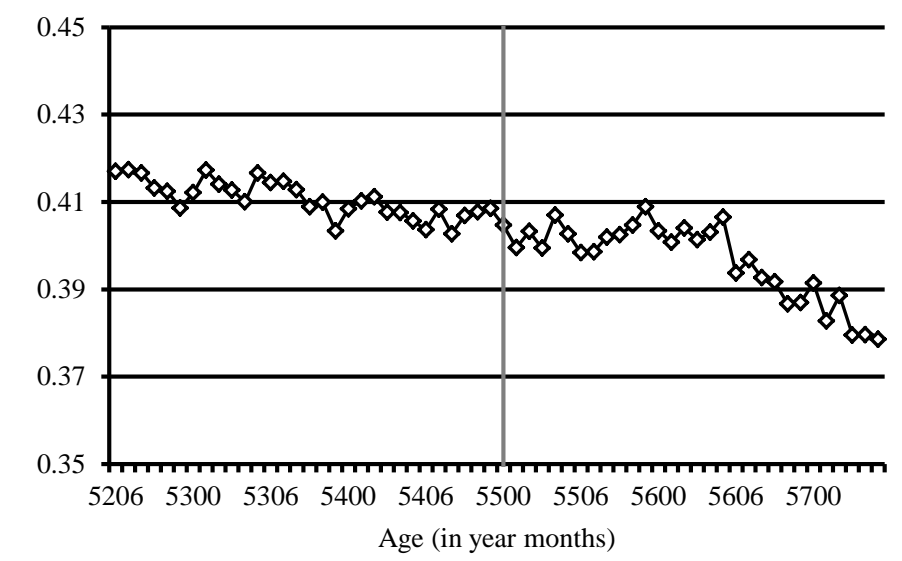

\section{G. Race (\% Chinese)}

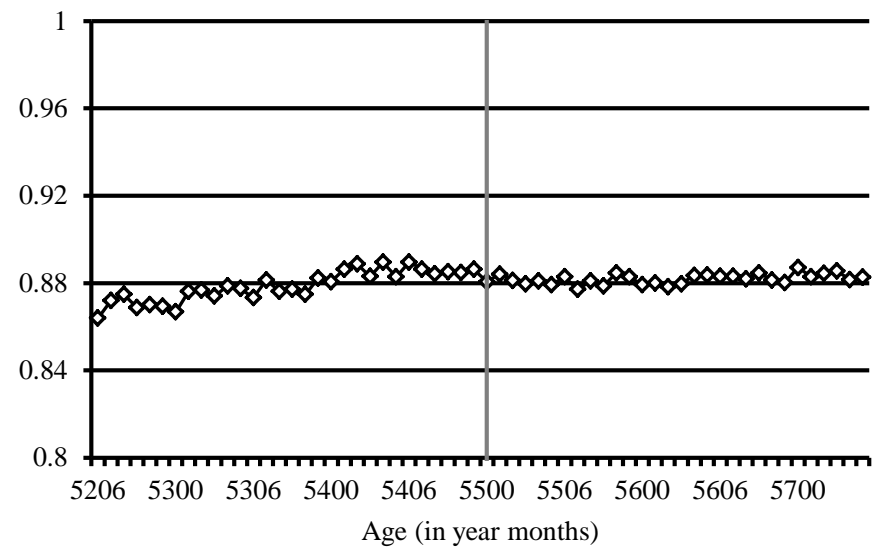

\section{F. Marital status (\% married)}

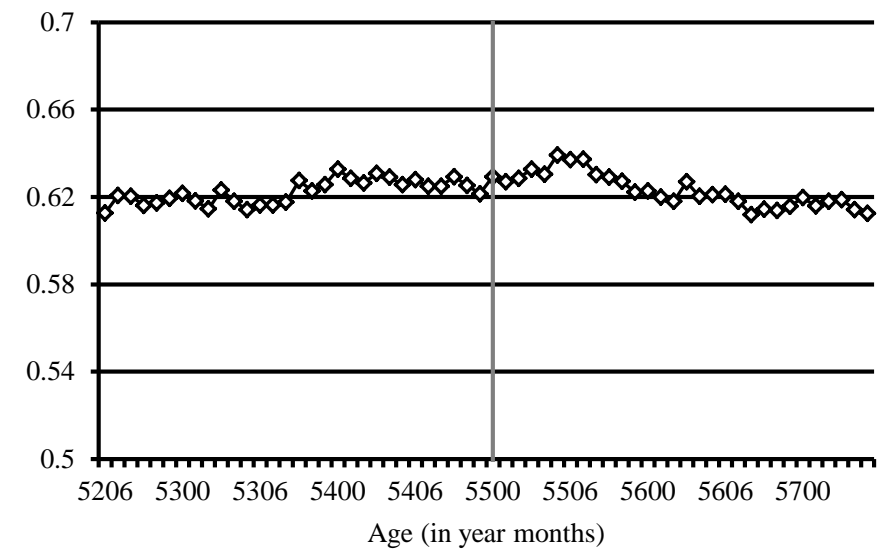


Figure 2: Dynamic Responses of Account Balances, Spending and Debt
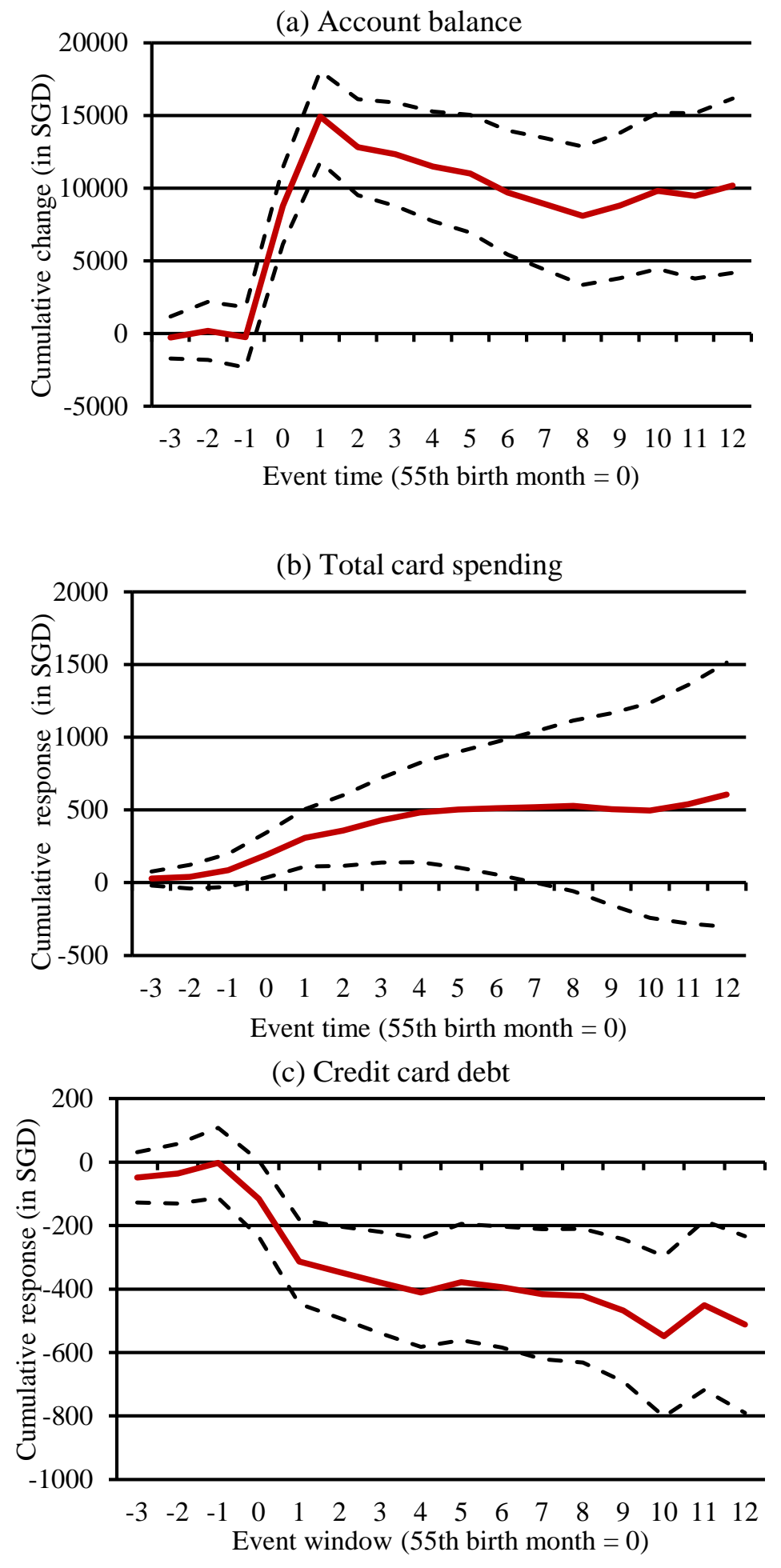


\section{Figure 2 (continued): Dynamic Responses of Account Balances, Spending and Debt}

(d) Debit card Spending

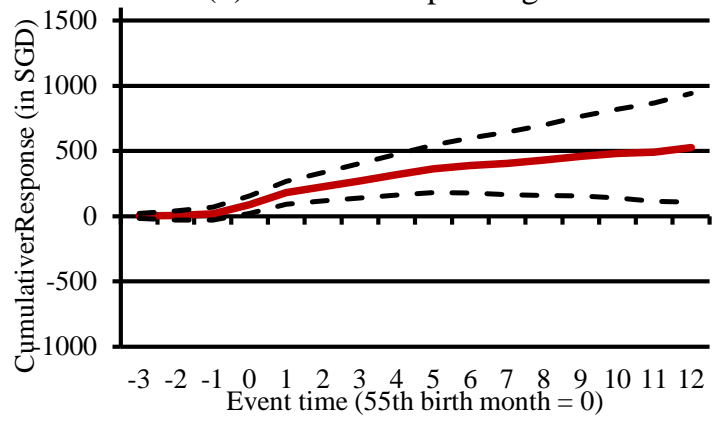

(e) Credit card Spending

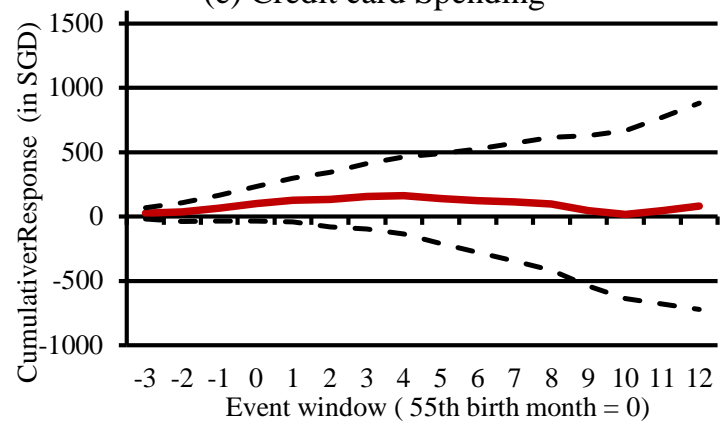

Note. This figure plots the entire path of coefficients from the estimation of Equation (2) for the three months before an individual turns 55 and up to twelve months after an individual turns 55, along with the corresponding 95 percent confidence intervals. For account balance and credit card debt, the figure indicates the change in balance and debt in each month, relative to the period four to six months before an individual turns 55. For spending, the figure plots the cumulative coefficient to derive the cumulative total spending at each point in time (also relative to the period at least four months before an individual turns 55). The marginal effect coefficients are reported in Table 2 . The $\mathrm{x}$-axis denotes the ith month before/after an individual turns 55 and the y-axis indicates the response in Singapore Dollars. 
Figure 3: Dynamic Responses of Account Balances, Spending and Debt by Liquidity Constraints

\section{Panel A. By credit card limit}

\section{Low Credit Limit}
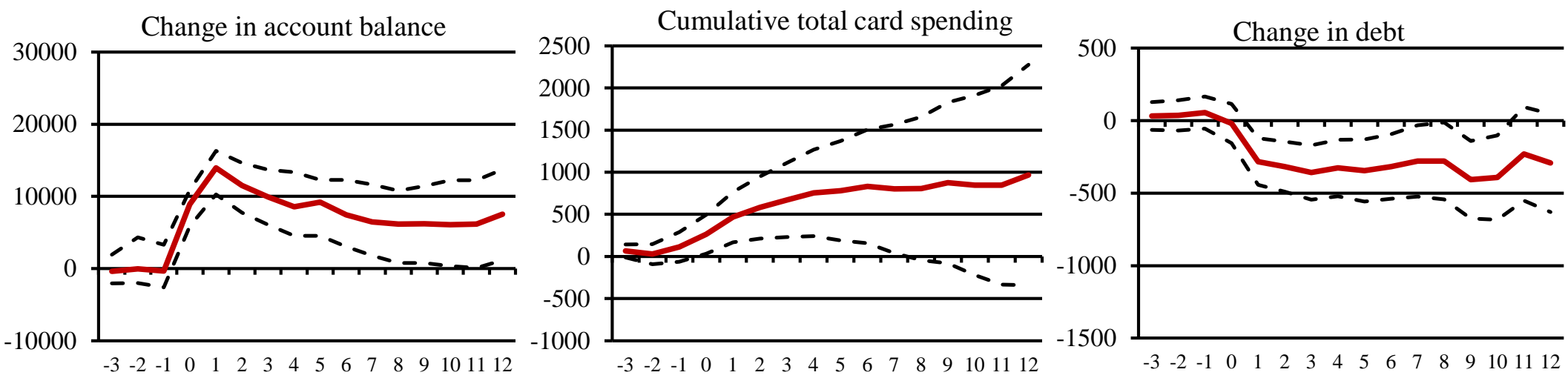

\section{High Credit Limit}
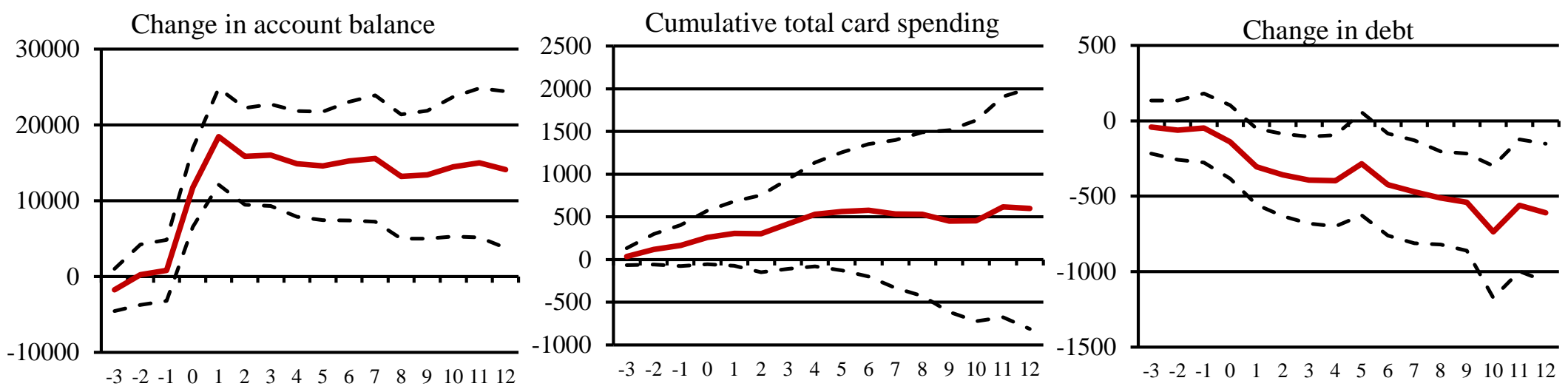

Note. This figure plots the dynamic responses of account balance, cumulative spending and debt for low-liquidity and high-liquidity consumers. Panel A uses credit limit as a proxy for liquidity constraints, Panel B uses monthly income and Panel C uses bank account balance. For this heterogeneity analysis, we use the first three months in our sample period to create the high and low threshold, and we drop the first three month observations as well as Singaporeans reaching 55 during those three months in this analysis. See text for more details on how these groups were constructed. The construction of the figures is similar to that in Figure 2. 


\section{Panel B: By income}

\section{Low income}
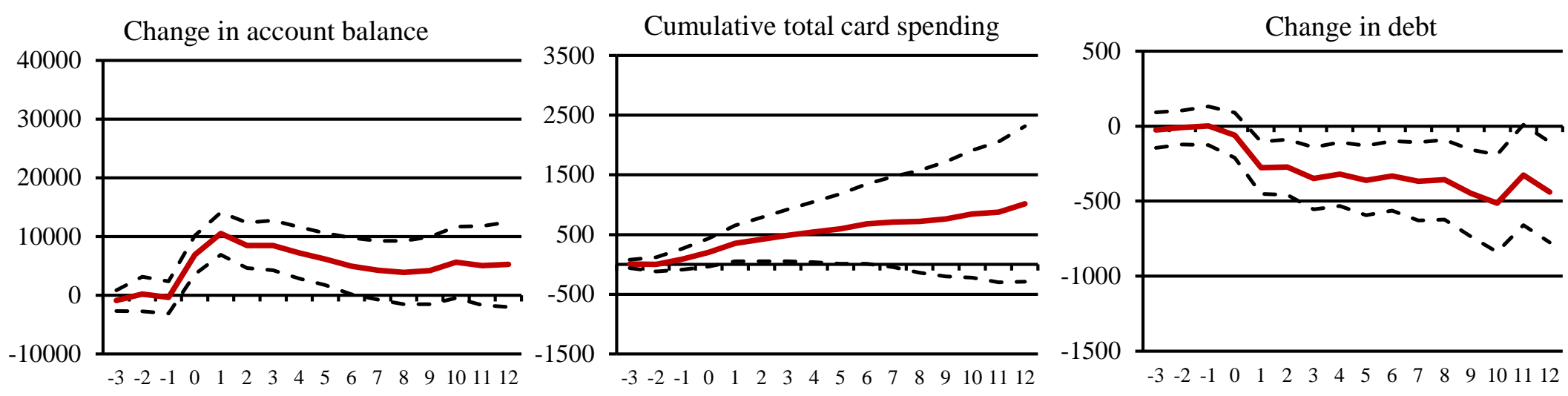

\section{High income}
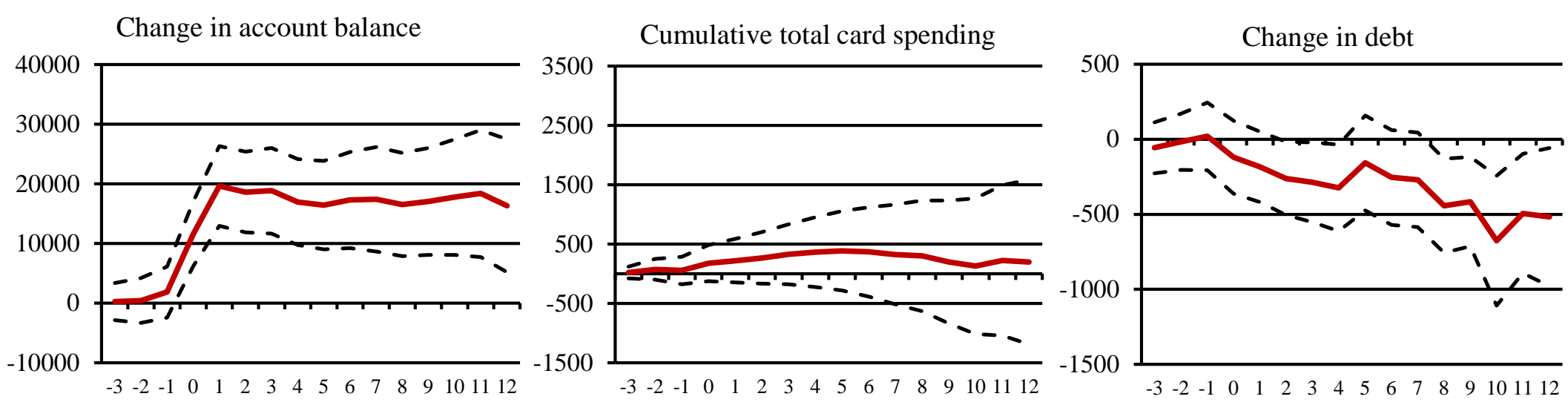


\section{Panel C: By pre-period bank account balance}

\section{Low balance}
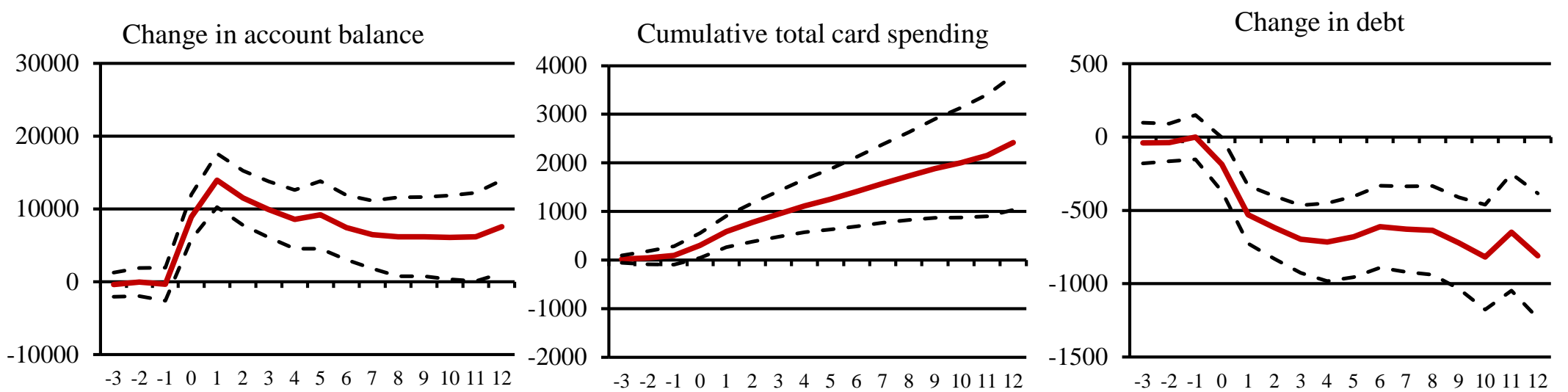

\section{High balance}
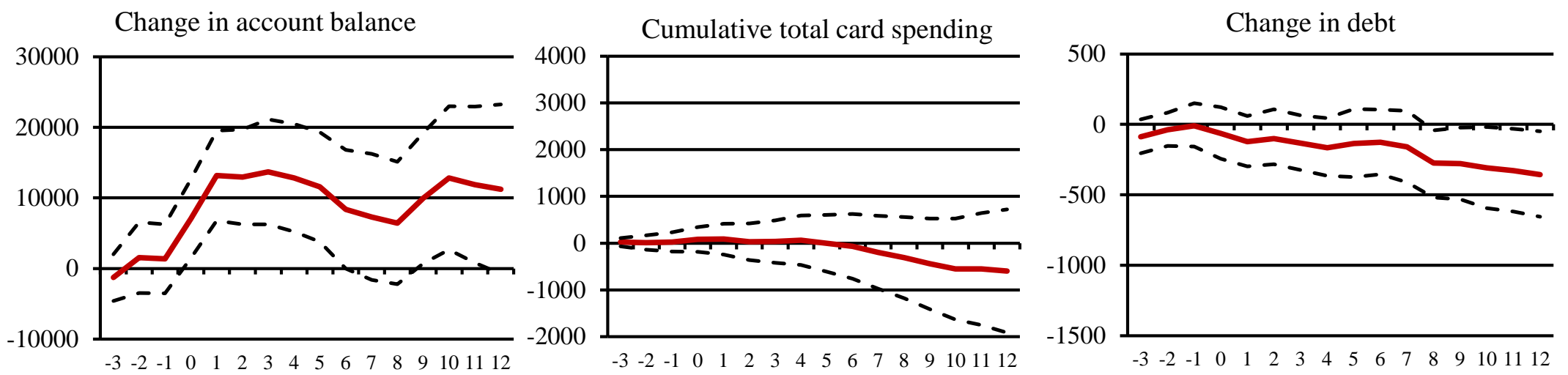
Table 1: Average Effect of Withdrawal Age on Account Balance, Spending and Debt

\begin{tabular}{|c|c|c|c|c|c|}
\hline & $\begin{array}{c}\text { Account } \\
\text { balance } \\
(1) \\
\end{array}$ & $\begin{array}{c}\text { Total card } \\
\text { spending } \\
(2) \\
\end{array}$ & $\begin{array}{c}\text { Debit card } \\
\text { spending } \\
(3)\end{array}$ & $\begin{array}{c}\text { Credit card } \\
\text { spending } \\
(4) \\
\end{array}$ & $\begin{array}{c}\text { Credit card } \\
\text { debt } \\
(5)\end{array}$ \\
\hline \multicolumn{6}{|l|}{ Before age 55} \\
\hline$(-3,-1$ month) window & $\begin{array}{c}872.11 \\
(878.60)\end{array}$ & $\begin{array}{c}55.15^{* * *} \\
(18.16)\end{array}$ & $\begin{array}{c}23.34^{* * *} \\
(7.86)\end{array}$ & $\begin{array}{c}31.81^{* *} \\
(16.05)\end{array}$ & $\begin{array}{c}56.69 \\
(44.03)\end{array}$ \\
\hline \multicolumn{6}{|l|}{ After age 55} \\
\hline ( 0,12 months) window & $\begin{array}{c}12,571.47^{* * *} \\
(1,426.17)\end{array}$ & $\begin{array}{c}95.72 * * * \\
(23.42)\end{array}$ & $\begin{array}{c}\text { 73.74*** } \\
(11.12)\end{array}$ & $\begin{array}{c}21.98 \\
(20.28)\end{array}$ & $\begin{array}{c}-210.71^{* * *} \\
(58.16)\end{array}$ \\
\hline Observations & 58,535 & 58,581 & 58,581 & 58,581 & 25,183 \\
\hline R-squared & 0.836 & 0.481 & 0.501 & 0.466 & 0.814 \\
\hline
\end{tabular}

Note. Each column is a separate regression of the outcome on a dummy indicating individuals 3 months before they turn 55 and a dummy indicating individuals 0 to 12 months after they turn 55 . The effects are estimated relative to the omitted group which comprises individuals when they are at least 4 months prior to turning 55 . All specifications include individual fixed effects and year*month fixed effects. Standard errors clustered at the individual level are reported in parentheses. ${ }^{* * *}$ significant at 1 percent, $* * 5$ percent, $* 1$ percent. 
Table 2: Response Dynamics to Reaching the Withdrawal Age

\begin{tabular}{|c|c|c|c|c|c|}
\hline & $\begin{array}{c}\text { Account } \\
\text { balance } \\
\text { (1) }\end{array}$ & $\begin{array}{l}\text { Total card } \\
\text { spending } \\
\text { (2) }\end{array}$ & $\begin{array}{c}\text { Debit card } \\
\text { spending } \\
\text { (3) }\end{array}$ & $\begin{array}{c}\text { Credit card } \\
\text { spending } \\
\text { (4) }\end{array}$ & $\begin{array}{c}\text { Credit card } \\
\text { debt } \\
\text { (5) }\end{array}$ \\
\hline \multirow{2}{*}{ - 3 months } & -265.34 & 29.30 & 3.04 & 26.26 & -48.23 \\
\hline & (732.38) & $(24.41)$ & $(9.94)$ & (22.07) & (40.33) \\
\hline \multirow[t]{2}{*}{ - 2 months } & 200.24 & 11.72 & 2.82 & 8.90 & -36.43 \\
\hline & $(1,016.37)$ & (25.83) & (10.78) & $(22.92)$ & $(47.92)$ \\
\hline \multirow{2}{*}{ - 1 month } & -245.91 & $43.88^{*}$ & 14.13 & 29.74 & -1.94 \\
\hline & $(1,059.19)$ & $(26.22)$ & (11.18) & (23.12) & $(56.26)$ \\
\hline \multirow{2}{*}{ Age 55} & $8,795.75^{* * *}$ & $105.32 * * *$ & $70.09 * * *$ & 35.23 & $-115.52 *$ \\
\hline & $(1,341.28)$ & (28.77) & (13.63) & (24.93) & $(61.41)$ \\
\hline \multirow{2}{*}{ + 1 month } & $14,933.10^{* * *}$ & $117.81^{* * *}$ & $90.10^{* * *}$ & 27.70 & $-313.76^{* * *}$ \\
\hline & $(1,598.90)$ & (31.04) & $(14.82)$ & (26.65) & (67.88) \\
\hline \multirow{2}{*}{ + 2 months } & $12,831.77 * * *$ & 50.17 & $45.89 * * *$ & 4.29 & $-347.09 * * *$ \\
\hline & $(1,682.31)$ & (31.33) & (14.06) & $(27.72)$ & (73.75) \\
\hline \multirow{2}{*}{ + 3 months } & $12,351.70 * * *$ & $70.80 * *$ & $45.86^{* * *}$ & 24.94 & $-379.57 * * *$ \\
\hline & $(1,809.65)$ & (33.76) & $(15.35)$ & (30.09) & $(81.34)$ \\
\hline \multirow{2}{*}{ + 4 months } & $11,510.60 * * *$ & 54.03 & $47.55^{* * *}$ & 6.48 & $-411.24 * * *$ \\
\hline & $(1,925.58)$ & $(34.20)$ & (16.06) & (30.38) & (87.09) \\
\hline \multirow{2}{*}{+5 months } & $11,009.19 * * *$ & 18.93 & $43.00 * * *$ & -24.07 & $-378.02 * * *$ \\
\hline & $(2,062.93)$ & (36.88) & $(16.47)$ & (32.51) & (93.39) \\
\hline \multirow{2}{*}{+6 months } & $9,708.27 * * *$ & 9.55 & 26.22 & -16.67 & $-393.87 * * *$ \\
\hline & $(2,177.85)$ & (37.74) & (17.59) & (33.64) & (97.29) \\
\hline \multirow[t]{2}{*}{+7 months } & 8,917.89*** & 7.45 & 16.61 & -9.16 & $-415.95 * * *$ \\
\hline & $(2,314.06)$ & (40.91) & (18.23) & (36.47) & (104.34) \\
\hline \multirow{2}{*}{ + 8 months } & $8,116.22 * * *$ & 9.38 & 23.51 & -14.13 & $-421.08 * * *$ \\
\hline & $(2,424.73)$ & (42.18) & (19.81) & (37.35) & (107.33) \\
\hline \multirow{2}{*}{ + 9 months } & 8,816.63*** & -23.12 & 31.35 & -54.47 & $-467.53 * * *$ \\
\hline & $(2,546.90)$ & (45.76) & (20.86) & (40.38) & (114.39) \\
\hline \multirow{2}{*}{ + 10 months } & $9,826.49 * * *$ & -8.81 & 20.31 & -29.13 & $-548.55^{* * *}$ \\
\hline & $(2,735.66)$ & (48.67) & (22.07) & (42.69) & (128.80) \\
\hline \multirow{2}{*}{ + 11 months } & $9,480.92 * * *$ & 42.93 & 11.81 & 31.12 & $-451.19 * * *$ \\
\hline & $(2,903.89)$ & (51.19) & (22.31) & (45.62) & $(135.70)$ \\
\hline \multirow{2}{*}{ + 12 months } & $10,182.21^{* * *}$ & 66.04 & 32.64 & 33.40 & $-511.61^{* * *}$ \\
\hline & $(3,060.87)$ & (54.56) & (24.58) & (48.57) & (141.94) \\
\hline Observations & 58,535 & 58,581 & 58,581 & 58,581 & 25,183 \\
\hline R-squared & 0.836 & 0.481 & 0.502 & 0.466 & 0.814 \\
\hline
\end{tabular}

Note. Each column is a separate regression of Equation (2) on different outcome variables. The effects are estimated relative to the omitted group which comprises individuals when they are at least four months prior to turning 55. All specifications include individual fixed effects and year*month fixed effects. Standard errors clustered at the individual level are reported in parentheses. ${ }^{* * *}$ significant at 1 percent, ${ }^{* * 5}$ percent, ${ }^{*} 1$ percent. 
Table 3: The Average Spending and Debt Response to the 2011 Growth Dividend Program

\begin{tabular}{lcccc}
\hline & $(1)$ & $(2)$ & $(3)$ & $(4)$ \\
& Total card spending & Debit card spending & Credit card spending & Credit card debt change \\
\hline \multirow{3}{*}{ \$ D x $1_{>\text {pre }}$} & 0.021 & 0.008 & 0.012 & -0.006 \\
& $(0.056)$ & $(0.032)$ & $(0.043)$ & $(0.025)$ \\
\$ D x 1 $1_{\text {p post }}$ & $0.110^{* *}$ & $0.069^{* *}$ & 0.041 & -0.002 \\
& $(0.055)$ & $(0.034)$ & $(0.041)$ & $(0.022)$ \\
Constant & & & & \\
& $1,095.463^{* * *}$ & $452.496^{* * *}$ & $642.967^{* * *}$ & $20.108^{* *}$ \\
R-squared & $(18.706)$ & $(8.057)$ & $(17.459)$ & $(9.902)$ \\
\hline
\end{tabular}

Note. This table shows the average spending and debt (change) response of the Singaporeans who reach 55 during our sample period to the Growth Dividend announced (distributed) by the Singapore government in February (April) 2011. The sample in analysis covers the period from 2010:08 to 2011:11. $\$ D$ is the amount of the Growth Dividend received for the treatment group (Singaporeans who turn 55 during our sample period), and is equal to zero for the control group (non-Singaporeans who are otherwise similar, identified as the nearest neighbor from the propensity score matching analysis). $1_{\text {pre }}$ is a binary variable equal to one for the four months before the announcement (i.e., 2010:10-2011:01). $1_{\text {post }}$ is a binary variable equal to one for the months after the announcement of the Growth Dividend Program (i.e., >= 2011:02). Please refer to Agarwal and Qian (2014) for details on the Growth Dividend program and the empirical specification (Table 2 in their paper). Individual and year-month fixed effects are included. Standard errors clustered at the individual level are reported in parentheses. ${ }^{* * *}$ significant at 1 percent, **5 percent, * ${ }^{*}$ percent. 
Table 4: Falsification Tests

\begin{tabular}{|c|c|c|c|c|c|}
\hline & $\begin{array}{c}\text { Account } \\
\text { balance } \\
(1)\end{array}$ & $\begin{array}{c}\text { Total card } \\
\text { spending } \\
(2)\end{array}$ & $\begin{array}{c}\text { Debit card } \\
\text { spending } \\
\text { (3) }\end{array}$ & $\begin{array}{c}\text { Credit card } \\
\text { spending } \\
\text { (4) }\end{array}$ & $\begin{array}{c}\text { Credit card } \\
\text { debt } \\
\text { (5) }\end{array}$ \\
\hline & \multicolumn{5}{|c|}{ Sample: Foreigners around age 55} \\
\hline $\begin{array}{l}\text { Before age } 55 \\
\quad(-3,-1 \text { month) window }\end{array}$ & $\begin{array}{c}2,205.04 \\
(3,049.96)\end{array}$ & $\begin{array}{c}72.87 \\
(122.72)\end{array}$ & $\begin{array}{l}-38.38 \\
(45.54)\end{array}$ & $\begin{array}{c}111.25 \\
(108.93)\end{array}$ & $\begin{array}{c}477.59 \\
(295.34)\end{array}$ \\
\hline $\begin{array}{l}\text { After age } 55 \\
(0,12 \text { months }) \text { window }\end{array}$ & $\begin{array}{c}3,537.24 \\
(4,045.11)\end{array}$ & $\begin{array}{c}-46.15 \\
(139.15)\end{array}$ & $\begin{array}{c}-7.24 \\
(46.63)\end{array}$ & $\begin{array}{c}-38.91 \\
(126.04)\end{array}$ & $\begin{array}{c}221.91 \\
(334.22)\end{array}$ \\
\hline $\begin{array}{l}\text { Observations } \\
\text { R-squared }\end{array}$ & $\begin{array}{l}2,138 \\
0.789\end{array}$ & $\begin{array}{l}2,192 \\
0.562\end{array}$ & $\begin{array}{l}2,192 \\
0.577\end{array}$ & $\begin{array}{l}2,192 \\
0.580\end{array}$ & $\begin{array}{l}1,058 \\
0.787\end{array}$ \\
\hline \multicolumn{6}{|c|}{ Sample: Singaporeans around age 50} \\
\hline $\begin{array}{l}\text { Before age } 50 \\
\qquad(-3,-1 \text { month) window }\end{array}$ & $\begin{array}{l}-321.71 \\
(667.89)\end{array}$ & $\begin{array}{c}-4.42 \\
(14.35)\end{array}$ & $\begin{array}{l}-1.95 \\
(6.64)\end{array}$ & $\begin{array}{c}-2.47 \\
(12.79)\end{array}$ & $\begin{array}{l}-20.37 \\
(35.40)\end{array}$ \\
\hline $\begin{array}{l}\text { After age } 50 \\
(0,12 \text { months }) \text { window }\end{array}$ & $\begin{array}{c}461.53 \\
(968.30)\end{array}$ & $\begin{array}{c}-8.91 \\
(19.36)\end{array}$ & $\begin{array}{l}-2.60 \\
(8.82)\end{array}$ & $\begin{array}{c}-6.31 \\
(17.18)\end{array}$ & $\begin{array}{c}18.19 \\
(53.16)\end{array}$ \\
\hline Observations & 78,064 & 78,122 & 78,122 & 78,122 & 34,066 \\
\hline R-squared & 0.848 & 0.489 & 0.510 & 0.479 & 0.854 \\
\hline
\end{tabular}

Note. Each column is a separate regression of the outcome on a dummy indicating individuals 3 months before they turn 55 and a dummy indicating individuals zero to 12 months after they turn 55 . The effects are estimated relative to the omitted group which comprises individuals when they are four to six months prior to turning 55. All specifications include individual fixed effects and year*month fixed effects. Standard errors clustered at the individual level are reported in parentheses. ${ }^{* * *}$ significant at 1 percent, $* * 5$ percent, ${ }^{*} 1$ percent. 
Table 5: Determinants of Pension Savings Withdrawal

\begin{tabular}{|c|c|c|c|c|c|c|}
\hline \multirow[b]{2}{*}{ Demographics } & \multicolumn{3}{|c|}{$\begin{array}{c}\text { Dummy }=1 \\
\text { (if withdrawal amount }>75 \% \text { in the pre-55 } \\
\text { distribution of monthly change in balance) }\end{array}$} & \multicolumn{3}{|c|}{$\begin{array}{l}\text { Dummy }=1 \\
\text { (if withdrawal amount }>90 \% \text { in the pre-55 } \\
\text { distribution of monthly change in balance) }\end{array}$} \\
\hline & & & & & & \\
\hline Female & & $\begin{array}{l}-0.048 * * \\
(0.019)\end{array}$ & $\begin{array}{l}-0.045 * * \\
(0.019)\end{array}$ & & $\begin{array}{l}-0.072 * * * \\
(0.019)\end{array}$ & $\begin{array}{c}-0.067 * * * \\
(0.019)\end{array}$ \\
\hline Malay & & $\begin{array}{l}0.178 * * * \\
(0.042)\end{array}$ & $\begin{array}{l}0.166^{* * * *} \\
(0.041)\end{array}$ & & $\begin{array}{l}0.181^{* * *} \\
(0.041)\end{array}$ & $\begin{array}{l}0.169 * * * \\
(0.040)\end{array}$ \\
\hline Indian & & $\begin{array}{c}0.040 \\
(0.048)\end{array}$ & $\begin{array}{c}0.044 \\
(0.047)\end{array}$ & & $\begin{array}{c}0.059 \\
(0.048)\end{array}$ & $\begin{array}{c}0.067 \\
(0.046)\end{array}$ \\
\hline Married & & $\begin{array}{l}-0.018 \\
(0.020)\end{array}$ & $\begin{array}{l}-0.024 \\
(0.020)\end{array}$ & & $\begin{array}{l}-0.001 \\
(0.020)\end{array}$ & $\begin{array}{l}-0.008 \\
(0.019)\end{array}$ \\
\hline \multicolumn{7}{|l|}{ Occupation } \\
\hline Professional & & $\begin{array}{c}0.021 \\
(0.021)\end{array}$ & $\begin{array}{c}0.014 \\
(0.021)\end{array}$ & & $\begin{array}{c}0.023 \\
(0.021)\end{array}$ & $\begin{array}{c}0.012 \\
(0.020)\end{array}$ \\
\hline \multicolumn{7}{|l|}{ Banking Experience } \\
\hline $\log$ (Tenure in years at the bank) & & $\begin{array}{l}-0.011 \\
(0.033)\end{array}$ & $\begin{array}{l}-0.019 \\
(0.033)\end{array}$ & & $\begin{array}{c}0.040 \\
(0.033)\end{array}$ & $\begin{array}{c}0.029 \\
(0.032)\end{array}$ \\
\hline Priority bank account & & $\begin{array}{l}-0.029 \\
(0.037)\end{array}$ & $\begin{array}{l}-0.116^{* * * *} \\
(0.038)\end{array}$ & & $\begin{array}{c}0.020 \\
(0.037)\end{array}$ & $\begin{array}{l}-0.095^{* *} \\
(0.037)\end{array}$ \\
\hline \multicolumn{7}{|l|}{ Financial Variables } \\
\hline log (Average pre-55 monthly income) & $\begin{array}{c}0.003 \\
(0.009)\end{array}$ & & $\begin{array}{c}0.001 \\
(0.009)\end{array}$ & $\begin{array}{c}0.007 \\
(0.008)\end{array}$ & & $\begin{array}{c}0.002 \\
(0.009)\end{array}$ \\
\hline log (Average pre-55 monthly bank account balance) & $\begin{array}{l}0.058^{* * *} \\
(0.007)\end{array}$ & & $\begin{array}{l}0.065^{* * *} \\
(0.007)\end{array}$ & $\begin{array}{l}0.077 * * * \\
(0.006)\end{array}$ & & $\begin{array}{l}0.083^{* * *} \\
(0.007)\end{array}$ \\
\hline log (Average pre-55 monthly credit card debt) & $\begin{array}{l}0.021^{* * *} \\
(0.004)\end{array}$ & & $\begin{array}{l}0.019 * * * \\
(0.004)\end{array}$ & $\begin{array}{l}0.023^{* * *} \\
(0.003)\end{array}$ & & $\begin{array}{l}0.021^{* * *} \\
(0.003)\end{array}$ \\
\hline Observations & 2,733 & 2,733 & 2,733 & 2,733 & 2,733 & 2,733 \\
\hline R-squared & 0.035 & 0.011 & 0.049 & 0.059 & 0.015 & 0.075 \\
\hline
\end{tabular}

Note: This table shows the OLS regression results of the characteristics associated with pension savings withdrawals among the Singaporeans who turned 55 in our sample. The dependent variable in the first (second) three columns is a dummy variable equal to one if the change in bank account balance in the month Singaporeans turned 55 is greater than the 75 percent (90 percent) in the distribution of the average monthly change in balance in the pre-55 period among these individuals. Female is a dummy variable equal to one if the individual is female. Malay is a dummy variable equal to one if the individual is Malay in ethnicity. Indian is a dummy variable equal to one if the individual is Indian in ethnicity (for these ethnicity dummies, Chinese ethnic group is the omitted group). Professional is a dummy variable equal to one if the individual's occupation is classified as professional. Tenure in years at the bank measures the number of years' banking relationship with the bank, and Priority bank account is a dummy equal to one if the individual's bank account is the priority account, where the individual has access to privileged banking service and financial counselling. Average pre-55 monthly income (bank account balance, or credit card debt) is the average monthly income (bank account balance, or credit card debt) individuals have in the period before they reach 55 . ***significant at 1 percent, ** 5 percent, *1 percent. 


\section{Appendix}

\section{A. Overview of $\mathrm{CPF}$}

The Central Provident Fund (CPF) is a comprehensive social security savings plan covering the areas of retirement, healthcare, home ownership, family protection, and asset enhancement.

Working Singaporeans and their employers make monthly contributions to the CPF and these contributions are credited into the following three accounts:

1. Ordinary account (OA) - savings that can be used to buy a home, pay for CPF insurance, investment, and education

2. Special account (SA) - savings that can be used for old age and investment in retirement-related financial products

3. Medisave account - savings that can be used for hospitalization expenses and approved medical insurance

There are no age restrictions for the usage of funds in the OA and Medisave accounts as long as the savings in these accounts are used for their intended purposes. Savings in the SA can only be used to fund certain CPF-approved investment products (such as fixed deposits, government bonds and treasury bills, and selected insurance products) aimed at enhancing retirement assets. Importantly, all profits accrued to investment products ${ }^{35}$ financed using funds from the SA is credited to the SA and can only be withdrawn as part of an individual's retirement benefits at age 55 and 65 . Details on the CPF contribution rates and the allocation rules over an individual's lifecycle can be found at the following website: http://mycpf.cpf.gov.sg/Members/Gen-Info/Con-Rates/ContriRa.htm

B. Details on the Withdrawal rule at age 55

\section{i. CPF Savings at 55}

\section{- Overview}

At 55, two important changes occur to an individual's CPF savings. First, a retirement account (RA) is created to set aside the CPF Minimum Sum. Second, individuals are entitled to withdraw a portion of their CPF savings.

The retirement account (RA) is created by transferring the savings from an individual's Special Account (SA), Ordinary Account (OA), and then Medisave Account (MA) to make up the CPF Minimum Sum (MS) (see Section (iii) below for key details on the CPF Minimum Sum scheme). This amount will pay individuals a monthly income from their draw-down age (around 65).

35 Information on the instruments that can be invested using CPF funds can be found here: http://mycpf.cpf.gov.sg/NR/rdonlyres/DCD118FF-473E-4A5C-8A0F-

322687316646/0/INV_InstrumentsunderCPFIS.pdf 
The amount that can be withdrawn at age 55 depends on an individual's date of birth according to the table below. During our sample period from 2010 to 2012, the applicable withdrawal rule is 10 percent to 30 percent of available CPF cash balances. Note the withdrawal percentage rule is fixed within the same birth cohort. For example, those turning 55 in 2010 will always be able to withdraw 30 percent of the available CPF balances, even if they start their first withdrawal at age 56 (i.e., in year 2011) or after. CPF withdrawals are not subject to tax.

\section{A: Withdrawal of cash balances at $\mathbf{5 5}$}

\begin{tabular}{|c|c|}
\hline The Day You Turn 55 & $\begin{array}{c}\text { Applicable Withdrawal } \\
\text { Rule (\%) }\end{array}$ \\
\hline On or before 31 Dec 2008 & $50 \%$ \\
\hline 1 Jan 2009 - 31 Dec 2009 & $40 \%$ \\
\hline 1 Jan 2010 - 31 Dec 2010 & $30 \%$ \\
\hline 1 Jan 2011 - 31 Dec 2011 & $20 \%$ \\
\hline 1 Jan 2012 - 31 Dec 2012 & $10 \%$ \\
\hline On or after 1 Jan 2013 & $\begin{array}{l}\text { Cash balances can only be } \\
\text { withdrawn after setting aside } \\
\text { both the CPF Minimum Sum } \\
\text { and Medisave Minimum Sum }\end{array}$ \\
\hline
\end{tabular}

The withdrawal rule during our sample period is applied independently of the CPF Minimum Sum Scheme. Individuals are entitled to withdraw their available cash balances based on the applicable withdrawal rule whether or not they meet the CPF Minimum Sum. Individuals with an MS shortfall will use a portion of their future CPF contributions to make up for the shortfall in their Retirement Account. An individual with cash balances in excess of the CPF Minimum Sum will be allowed to withdraw the excess cash balances. Note that individuals who meet the CPF Minimum Sum in their retirement accounts and are still making monthly $\mathrm{CPF}$ contributions will continue to have an Ordinary Account (OA). CPF cash balances in excess of the prevailing CPF Minimum Sum will also be held in the OA.

\section{- Applicable Interest Rates on CPF Savings}

The Ordinary Account currently pays an interest of 2.5 percent per annum while the Special Account, Medisave Account, and Retirement Account pay interest of 4 percent per annum. ${ }^{36}$ In addition, the first $\$ 60,000$ of an individual's combined balances (with up to $\$ 20,000$ from the OA) earns an extra 1 percent per annum. All CPF accounts (OA/SA/MA/RA) earn a minimum interest of 2.5 percent. This is guaranteed by the Government and provided for in the CPF Act.

\section{- Application for CPF Savings Withdrawal at Age 55}

\footnotetext{
${ }^{36}$ From 1 Jan 2010, Retirement Account (RA) savings are invested in Singapore Government Securities (SGS) which earn a fixed coupon equal to either the 12-month average yield of the 10-year SGS plus 1\% at the point of issuance, or 4\%, whichever is the higher, adjusted yearly. Historically, the 10YSGS yield is lower than 4\% hence RA savings have earned a fixed coupon of 4\% (floor rate) since July 1999. Information on CPF interest rates and the historical series of $\mathrm{CPF}$ interest rates can be found here: http://mycpf.cpf.gov.sg/Members/Gen-Info/IntRates/?wbc_purpose=Bbp.
} 
The withdrawal application can be submitted two months before an individual's $55^{\text {th }}$ birthday. Individuals can apply to withdraw their CPF either online or by submitting a physical copy of the application form to the CPF board. The withdrawal application form can be found at this link: http://mycpf.cpf.gov.sg/NR/rdonlyres/3E499AEF-7351-48B7-A408D6AC8E2D25DF/0/FORM_RSD55.pdf

The application form prominently states that it takes 10 minutes to fill in the form. The CPF board also sends an advance withdrawal invitation with details on the withdrawal procedure to individuals about two months before their $55^{\text {th }}$ birthday. Monthly talks (in multiple languages) are held at the CPF board on the withdrawal option for those reaching $55 .{ }^{37}$ Upon application, the processing time typically ranges from two to ten working days (upon turning 55), and the receipt of the withdrawal is through direct transfer to the designated bank account of the member (and the member only).

\section{- Subsequent withdrawal post-55}

An individual who has not withdrawn their CPF at age 55 may do so anytime. If an individual has previously withdrawn from their CPF upon reaching 55, they will be eligible to withdraw yearly, on or after their birthday each year. In some cases, individuals may apply for another withdrawal within their birthday year. These exceptions include unemployment, or if an individual is self-employed and has not been continuously working or receiving income in any business or trade for six months before the date of the CPF withdrawal application. For the next withdrawal, individuals can withdraw all their eligible cash balances in their Retirement Account (the leftover portion based on their eligible cash balances at 55) as well as all cash balances in excess of the CPF Minimum Sum (MS) and Medisave Minimum Sum (MMS) prevailing at the time of withdrawal.

\section{- CPF Savings upon death}

Upon death, the CPF savings will be paid to the Public Trustee for distribution to the deceased family according to the intestacy laws. Individuals who wish to distribute their CPF savings differently from the intestacy laws can make a CPF nomination. There are no estate taxes in Singapore for deaths on or after 15 Feb 2008. CPF savings are not taxable in the event of death. The procedures for applying for withdrawal for the beneficiaries are similar to those for the CPF members (as mentioned above). ${ }^{38}$

\section{ii. $\quad$ Minimum Sum Requirements}

\section{- $\quad$ CPF Minimum Sum (MS)}

The CPF Minimum Sum (MS) scheme was introduced in 1987 to provide CPF members with a monthly income to support a basic standard of living during retirement. CPF members can

\footnotetext{
${ }^{37}$ Schedules of talks can be found here http://www.cpf.gov.sg/seminar/default.asp.

${ }^{38}$ Please see the linked document for details (http://mycpf.cpf.gov.sg/NR/rdonlyres/439094CA-A0E6-4624-B3710CB395611CAE/0/DistributionofCPFSavingsuponDeathofaCPFMember.pdf).
} 
apply to commence their monthly payouts from their Retirement Account when they reach their applicable Draw Down Age. The MS is adjusted each year to account for inflation, longer life expectancies and post-retirement needs. Individuals who are not able to set aside the full MS in cash can use their property, bought using CPF savings to pledge for up to half of the MS. The remaining MS shortfall will be met using a portion of future CPF inflows.

Table: CPF Minimum Sum

\begin{tabular}{|c|c|c|}
\hline $\begin{array}{c}\text { 55th birthday on or } \\
\text { after }\end{array}$ & $\begin{array}{c}\text { MS } \\
\text { (in 2003 } \\
\text { dollars) }\end{array}$ & $\begin{array}{c}\text { MS } \\
\text { (after adjustment for } \\
\text { inflation) }\end{array}$ \\
\hline 1 July 2003 & $\$ 80,000$ & $\$ 80,000$ \\
\hline 1 July 2004 & $\$ 84,000$ & $\$ 84,500$ \\
\hline 1 July 2005 & $\$ 88,000$ & $\$ 90,000$ \\
\hline 1 July 2006 & $\$ 92,000$ & $\$ 94,600$ \\
\hline 1 July 2007 & $\$ 96,000$ & $\$ 99,600$ \\
\hline 1 July 2008 & $\$ 100,000$ & $\$ 106,000$ \\
\hline 1 July 2009 & $\$ 104,000$ & $\$ 117,000$ \\
\hline 1 July 2010 & $\$ 108,000$ & $\$ 123,000$ \\
\hline 1 July 2011 & $\$ 112,000$ & $\$ 131,000$ \\
\hline 1 July 2012 & $\$ 113,000$ & $\$ 139,000$ \\
\hline 1 July 2013 & $\$ \mathbf{1 1 5 , 0 0 0}$ & $\mathbf{\$ 1 4 8 , 0 0 0}$ \\
\hline 1 July 2014 & $\begin{array}{c}\text { To be } \\
\text { announced }\end{array}$ \\
\hline
\end{tabular}

- Medisave Minimum Sum (MMS) and the Medisave Contribution Ceiling (MCC)

The Medisave Scheme comprises two important features: the Medisave Minimum Sum (MMS) and the Medisave Contribution Ceiling (MCC). The MMS is the amount a member needs to retain in his Medisave Account whenever he makes a CPF withdrawal at age 55 and above. In our sample, this Medisave MS is non-binding in the sense that individuals are entitled to withdraw 10-30 percent of their available cash balances before the MMS is set aside. Future withdrawals of excess cash balances over the CPF MS are subject to the Medisave MS.

The MCC, which was implemented on 1 April 1986, is the maximum amount that a member can contribute to and maintain in the Medisave Account. This is set at $\$ 5000$ above the Medisave MS. Any monies in the Medisave Account in excess of the MCC will be transferred to their Special Account (for members below 55 years old) or their Retirement Account (for members aged 55 and above). Both the MMS and the MCC are adjusted yearly to keep up with healthcare inflation.

Note that unlike the CPF Minimum Sum (MS), which is fixed for the group turning 55 in a particular year, the Medisave MS is adjusted annually to keep up with medical inflation. 
Information on the MMS amounts is summarized in the table below.

Table: Medisave Minimum Sum and Contribution Ceiling

\begin{tabular}{|l|c|c|}
\hline & Minimum Sum & Contribution Ceiling \\
\hline 2009 & $\$ 32,000$ & $\$ 37,000$ \\
\hline 2010 & $\$ 34,500$ & $\$ 39,500$ \\
\hline 2011 & $\$ 36,000$ & $\$ 41,000$ \\
\hline 2012 & $\$ 38,500$ & $\$ 43,500$ \\
\hline 2013 & $\$ 40,500$ & $\$ 45,500$ \\
\hline
\end{tabular}

\section{Other Changes to the CPF Policy at Age 55}

\section{$\underline{\text { CPF Contribution Rates }}$}

The CPF contribution rates are also a function of an individual's age. Appendix table 2 summarizes the CPF contribution rates in our sample period (Source: http://mycpf.cpf.gov.sg/Members/Gen-Info/Con-Rates/). 
Table: CPF Contribution Rates in Sample Period

\begin{tabular}{|c|c|c|c|c|c|c|c|c|c|c|c|c|}
\hline \multirow[t]{2}{*}{ Employee Age } & \multicolumn{3}{|c|}{ April 2010-Aug 2010} & \multicolumn{3}{|c|}{ Sept 2010-Feb 2011} & \multicolumn{3}{|c|}{ March 2011-Aug 2011} & \multicolumn{3}{|c|}{ Sept 2011 to Aug 2012} \\
\hline & Employer & Employee & Total & Employer & Employee & Total & Employer & Employee & Total & Employer & Employee & Total \\
\hline$<=35$ years & 14.5 & 20 & 34.5 & 15 & 20 & 35 & 15.5 & 20 & 35.5 & 16 & 20 & 36 \\
\hline $35-45$ years & 14.5 & 20 & 34.5 & 15 & 20 & 35 & 15.5 & 20 & 35.5 & 16 & 20 & 36 \\
\hline $45-50$ years & 14.5 & 20 & 34.5 & 15 & 20 & 35 & 15.5 & 20 & 35.5 & 16 & 20 & 36 \\
\hline 50-55 years & 10.5 & 18 & 28.5 & 11 & 18 & 29 & 11.5 & 18 & 29.5 & 12 & 18 & 30 \\
\hline 55-60 years & 7.5 & 12.5 & 20 & 8 & 12.5 & 20.5 & 8.5 & 12.5 & 21 & 9 & 12.5 & 21.5 \\
\hline 60-65 years & 5 & 7.5 & 12.5 & 5.5 & 7.5 & 13 & 6 & 7.5 & 13.5 & 6.5 & 7.5 & 14 \\
\hline$>65$ years & 5 & 5 & 10 & 5.5 & 5 & 10.5 & 6 & 5 & 11 & 6.5 & 5 & 11.5 \\
\hline
\end{tabular}


Figure A1.Time Distribution of 55th Birth Month

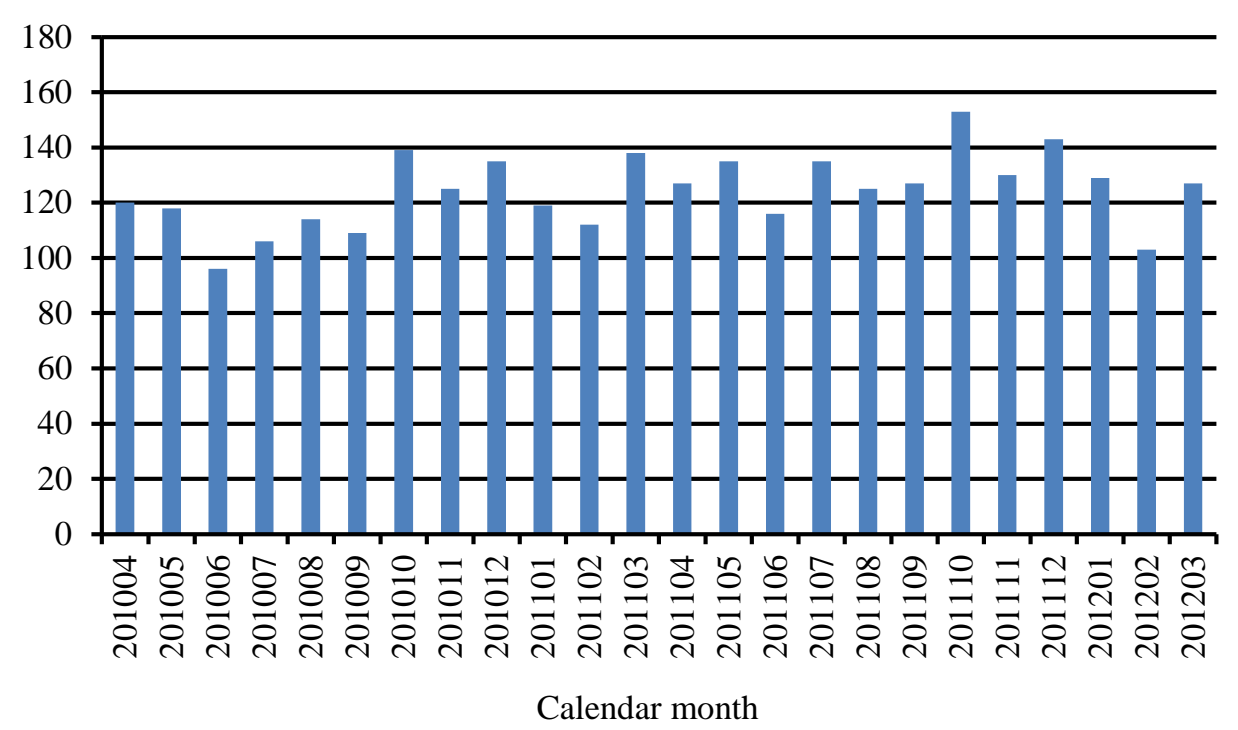

Note: This figure plots the histogram of the calendar months in which Singaporeans in our sample reach age 55. The $\mathrm{x}$-axis denotes the 24 months in our sample (2010:04-2012:03), and the y-axis denotes the number of Singaporeans reaching age 55 in each month. 


\section{Figure A2: More Heterogeneity Analysis of Responses of Account Balances, Spending and Debt}

\section{Panel A. By gender}

\section{Female}
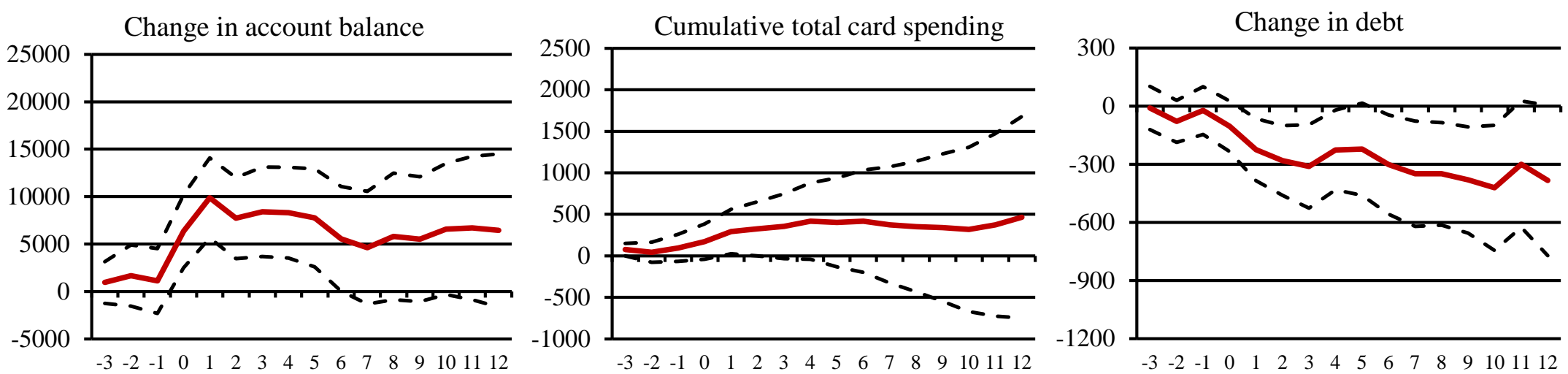

Male
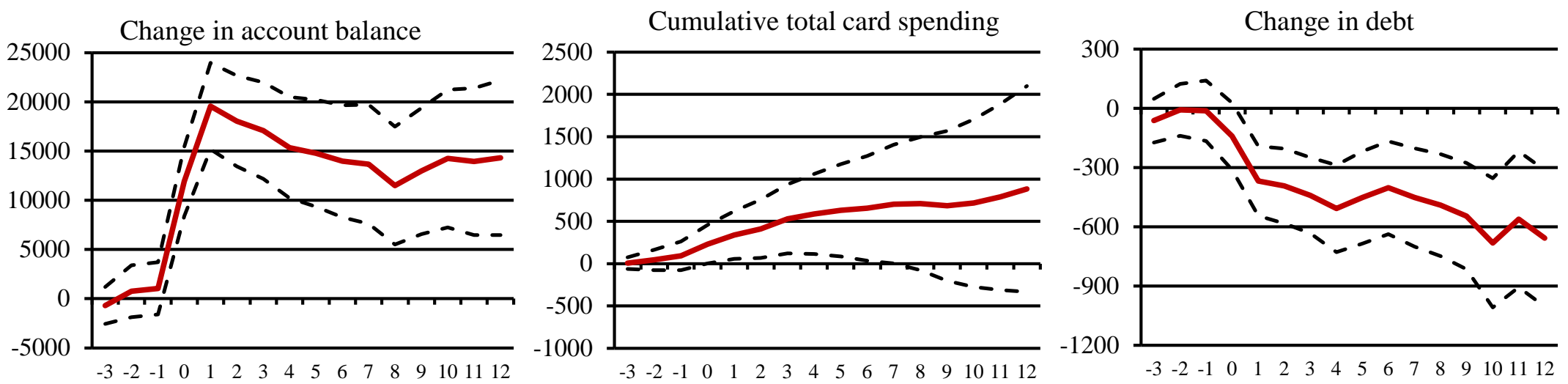

Note. This figure plots the dynamic responses of account balance, cumulative spending and debt for consumers with different demographics. Panel A compares the responses of female and male consumers, Panel B compares the responses of non-married and married consumers Panel C compares the responses of ethnically non-Chinese and ethnically Chinese Singaporeans, Panel D compares the responses among individuals turning 55 in 2010 vs. 2011 , and Panel E compares the responses among individuals with a joint bank account and those without a joint account. The construction of the figures is similar to that in Figure 2. 


\section{Panel B: By marital status}

\section{Unmarried}
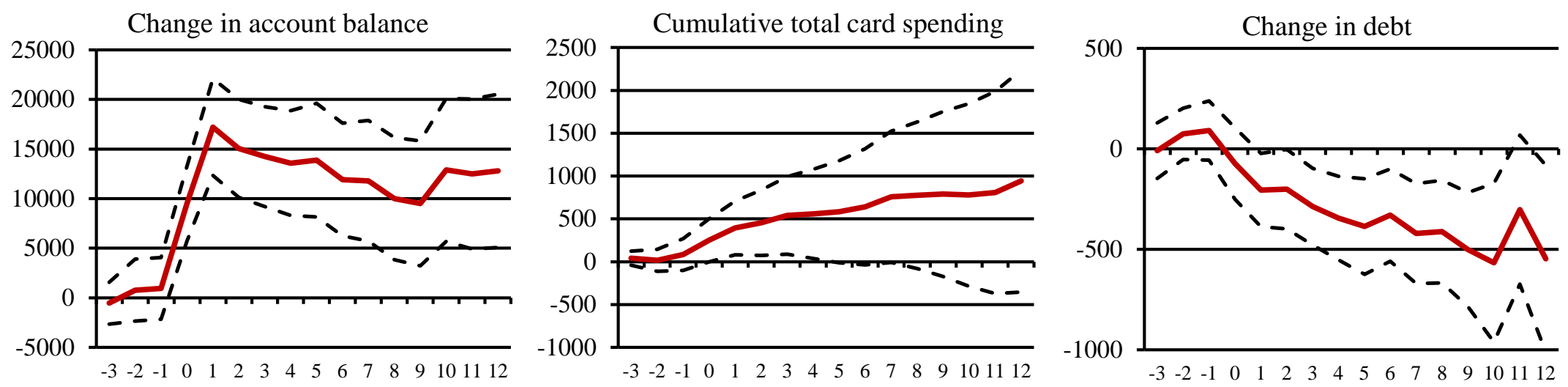

\section{$\underline{\text { Married }}$}
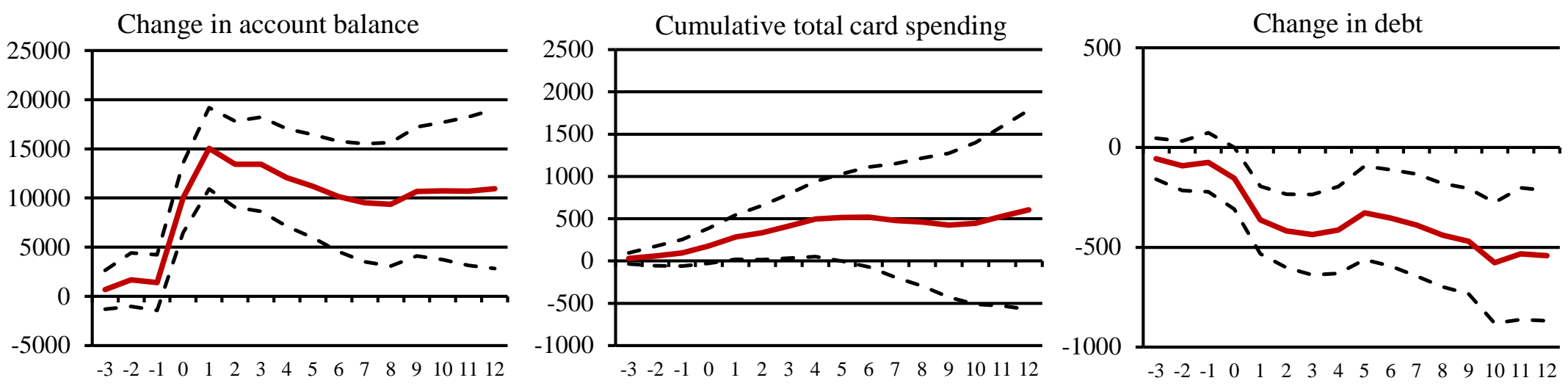


\section{Panel C: By ethnicity}

\section{Non-Chinese}
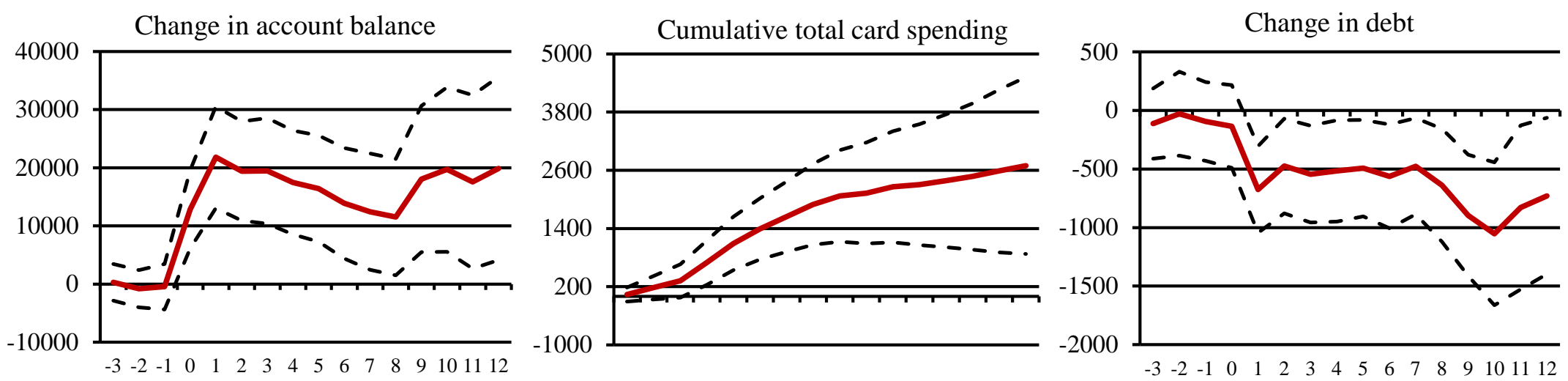

\section{Chinese}
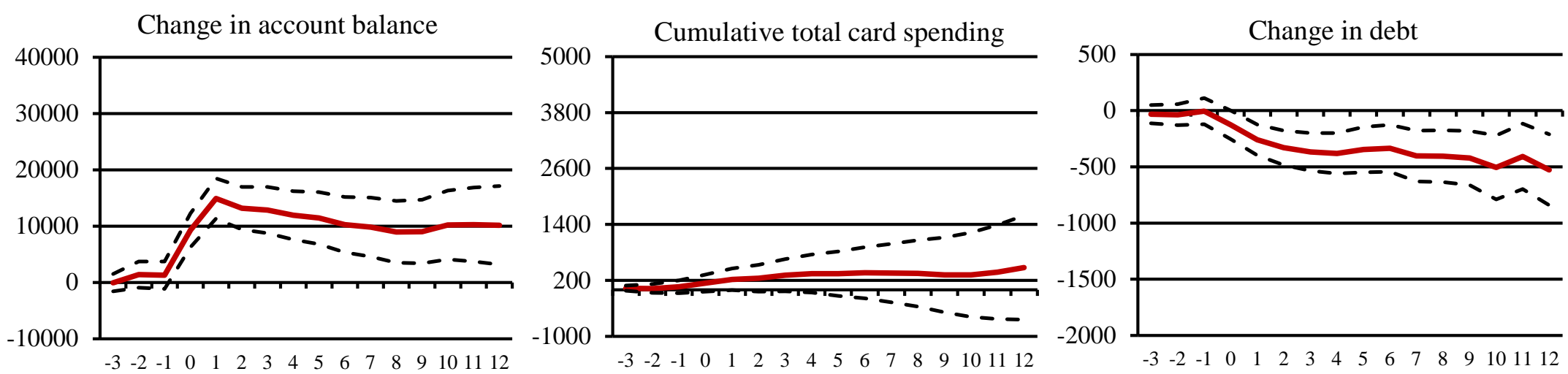
Panel D: By birth year

\section{Turning 55 in 2010}
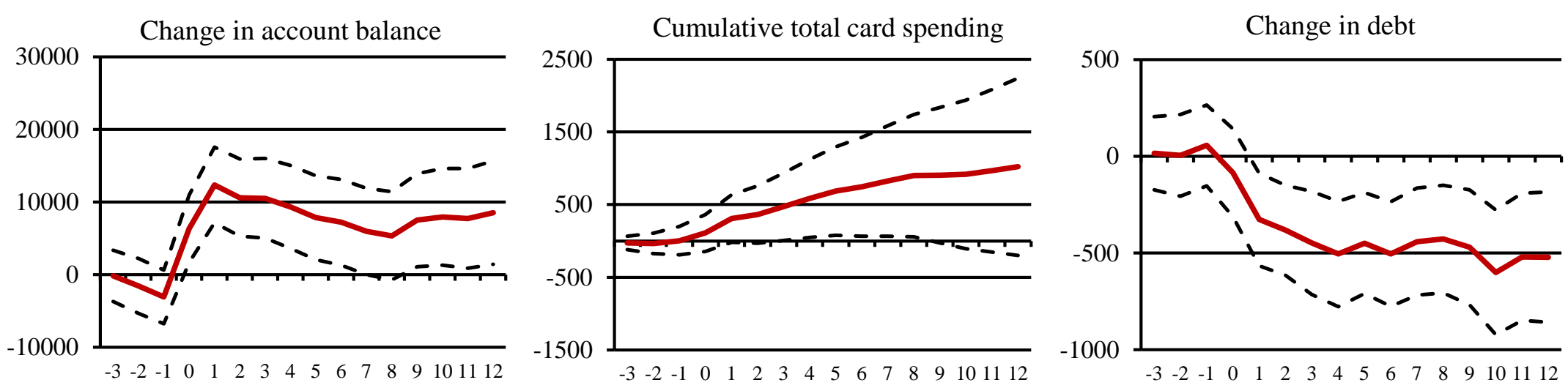

\section{$\underline{\text { Turning } 55 \text { in } 2011}$}
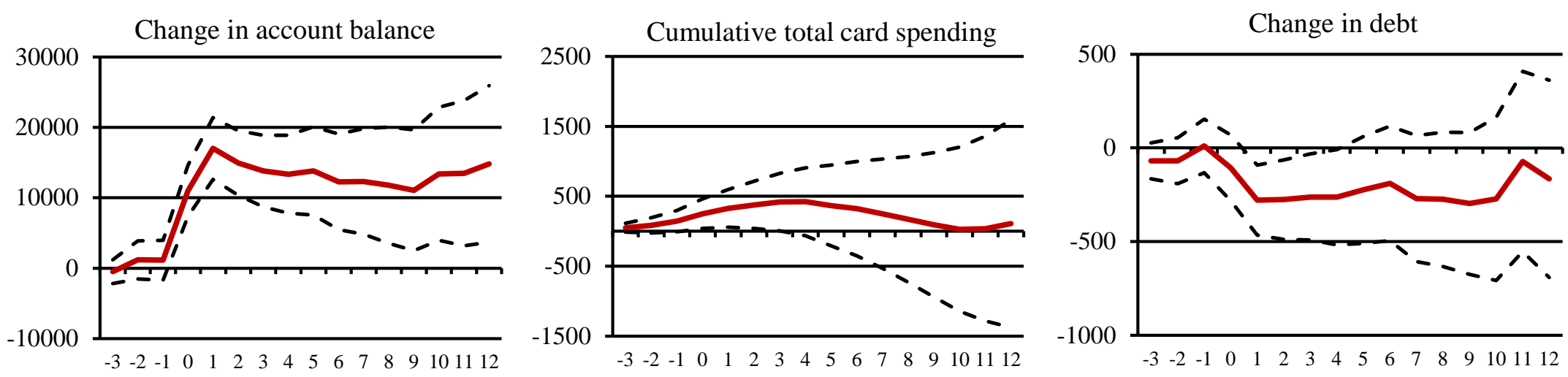


\section{Panel E: By bank account status}

\section{$\underline{\text { Joint account }}$}
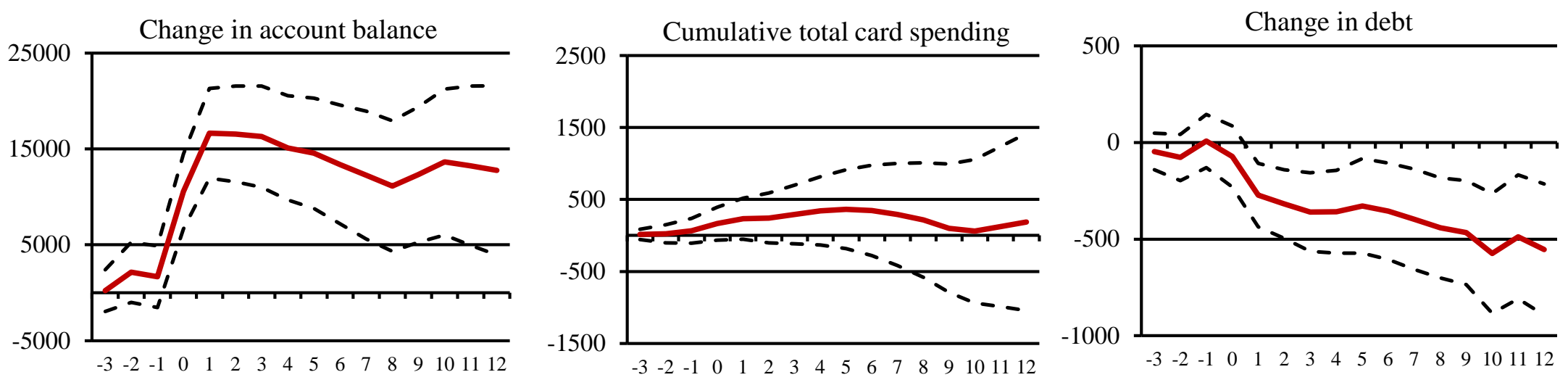

\section{Non-joint account}
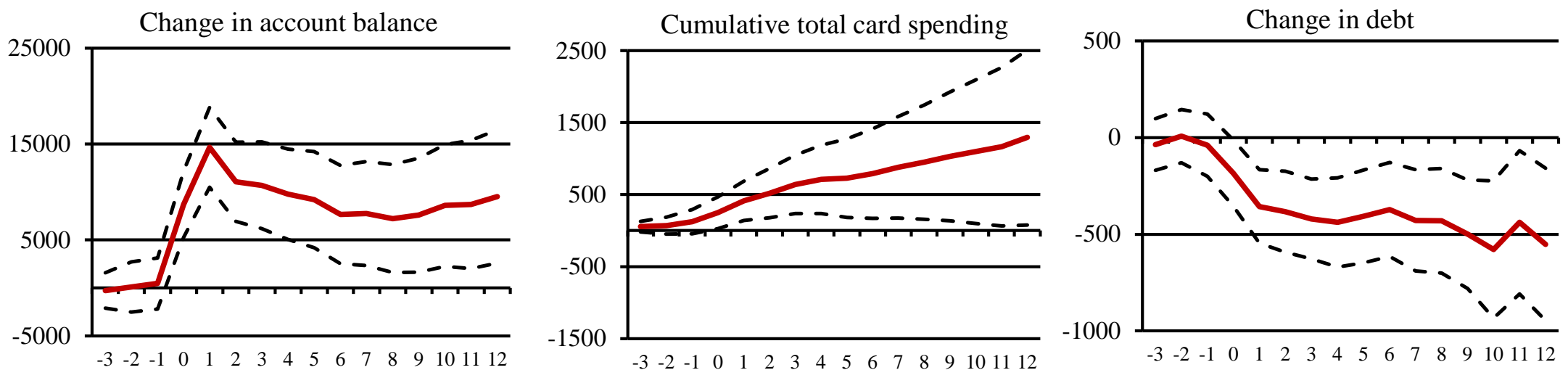
Figure A3: Post-55 Two Year Responses of Account Balances, Spending, and Debt

(a) Account balance

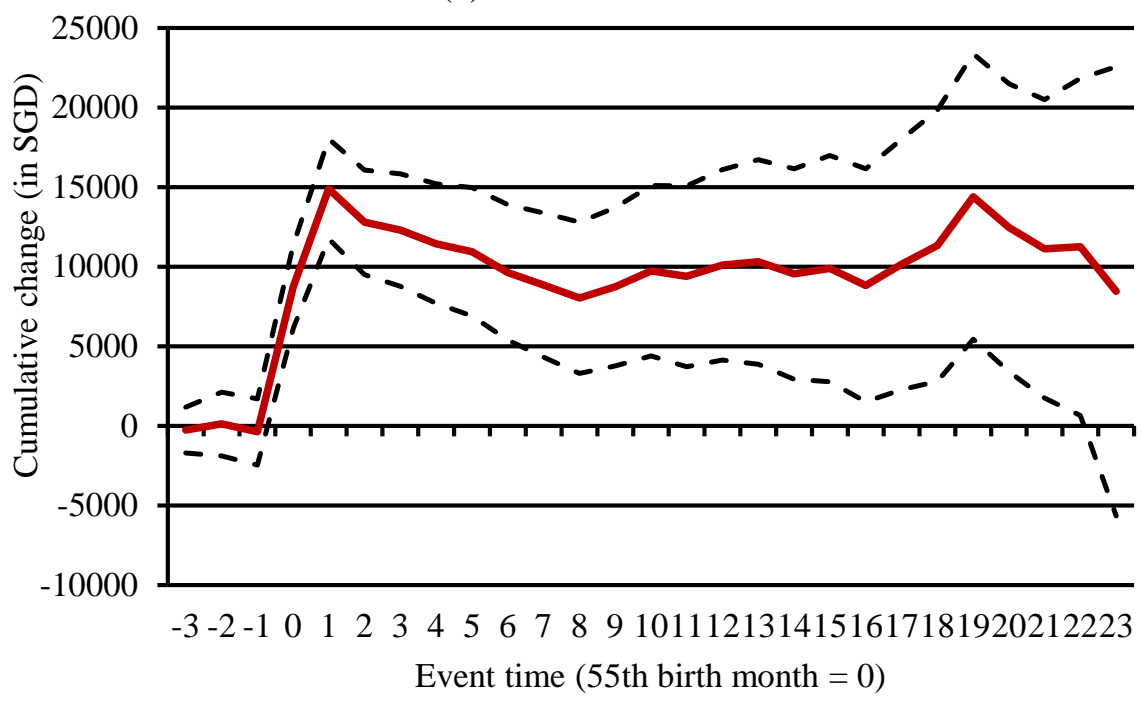

(b) Total card spending

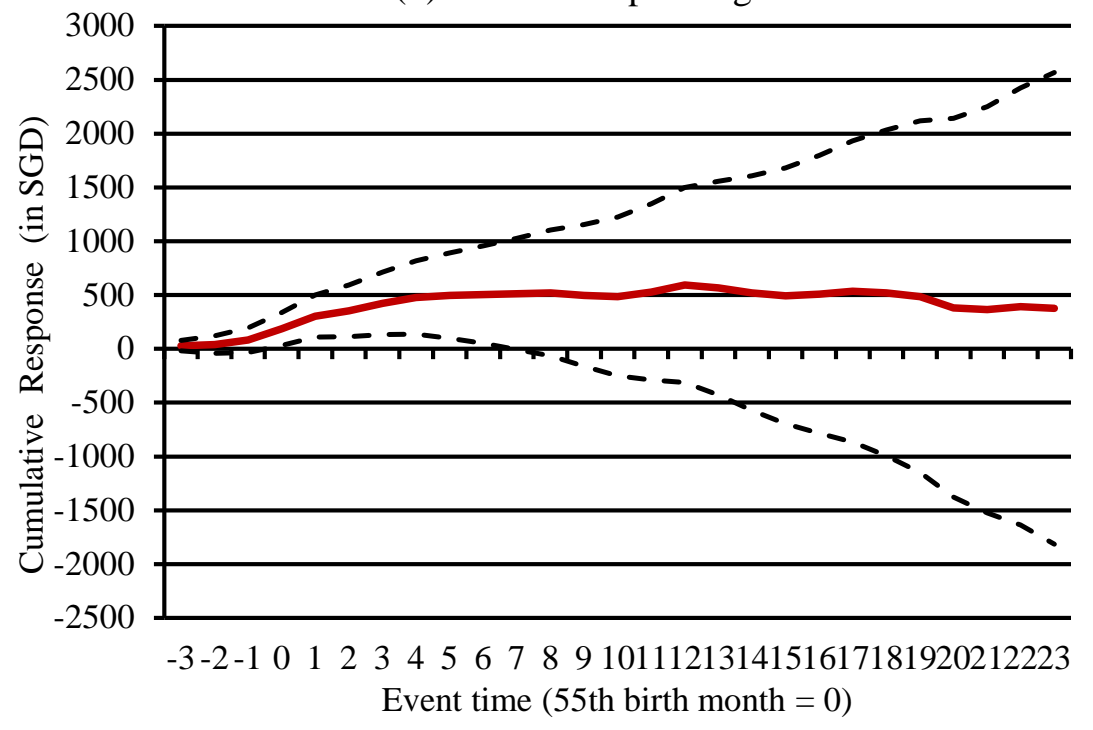


(e) Credit card debt

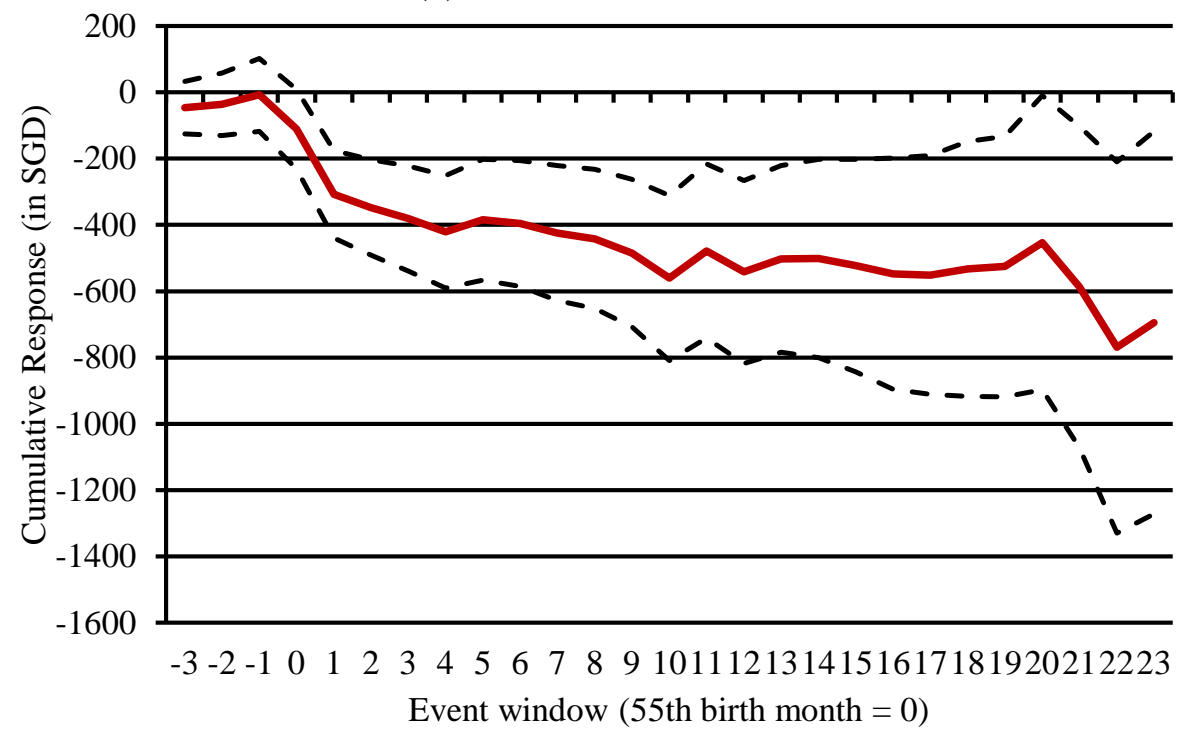

Note. This figure extends the dynamics in Figure 2 to the 24 month period after turning 55. The x-axis denotes the ith month before/after an individual turns 55 and the y-axis indicates the response in Singapore Dollars. 
Figure A4: Sample Statistics by Age (Foreigners around 55)

A. Bank account balance, by age

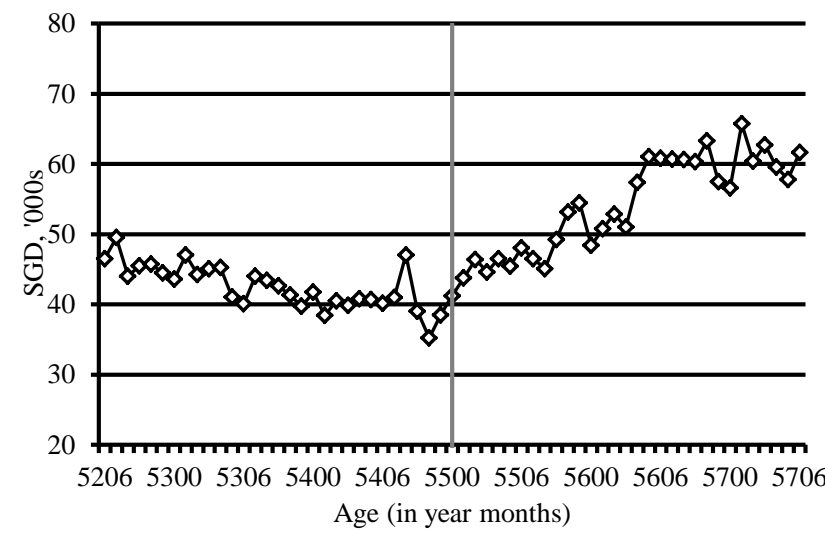

C. Monthly credit card debt

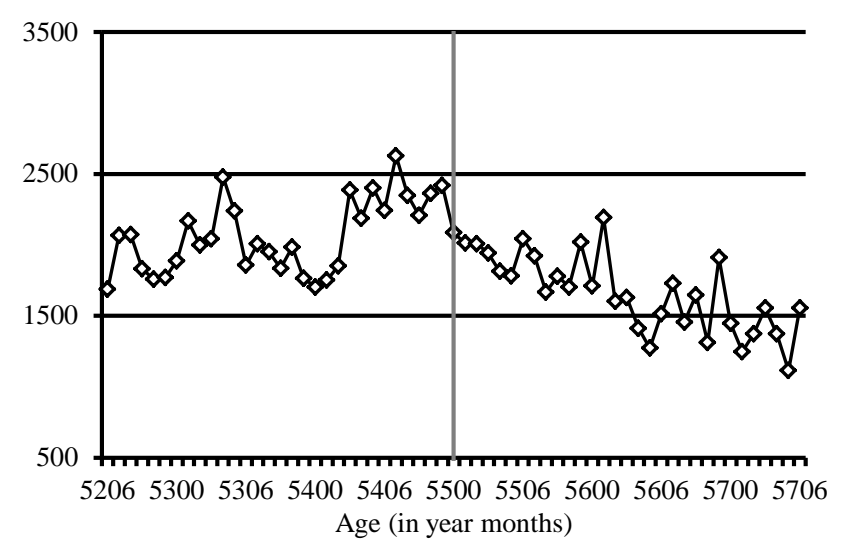

B. Total spending (Debit + Credit Card)

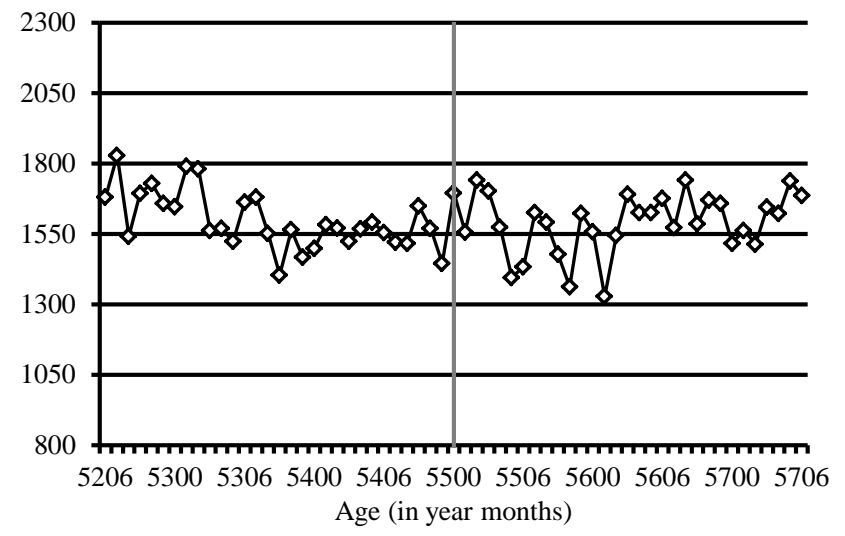

D. Monthly income

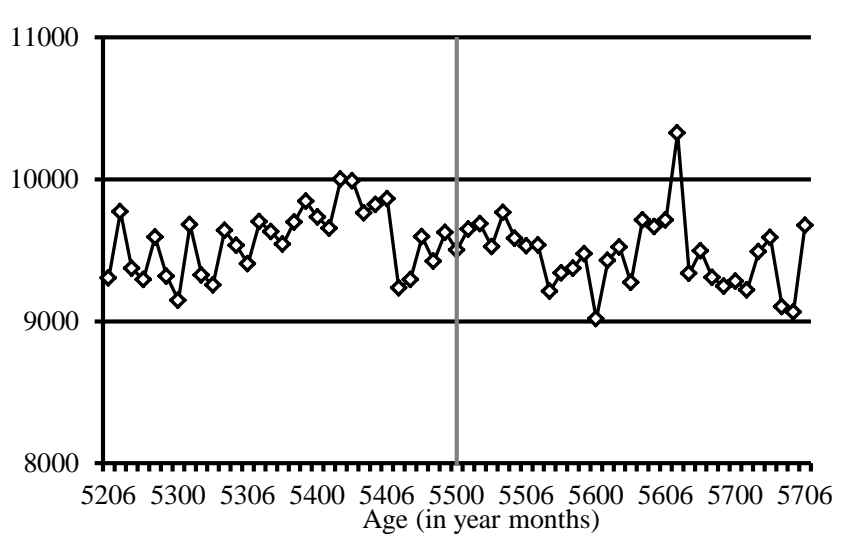

Note. Each panel plots the variable means by the age (in year-months). The sample includes all foreign individuals who turned 55 from April 2010 to March 2012. The vertical line indicates individuals in the sample who are age 55 and zero months. 


\section{E. Gender (\% female)}

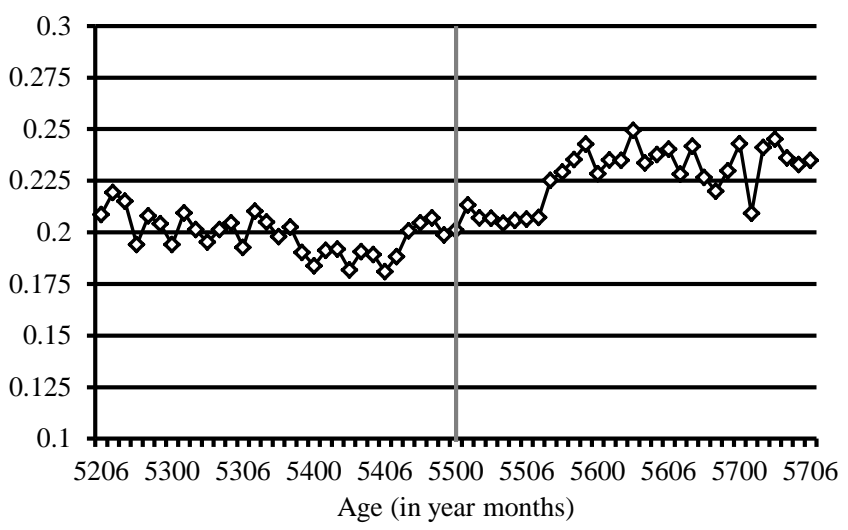

\section{F. Marital status (\% married)}

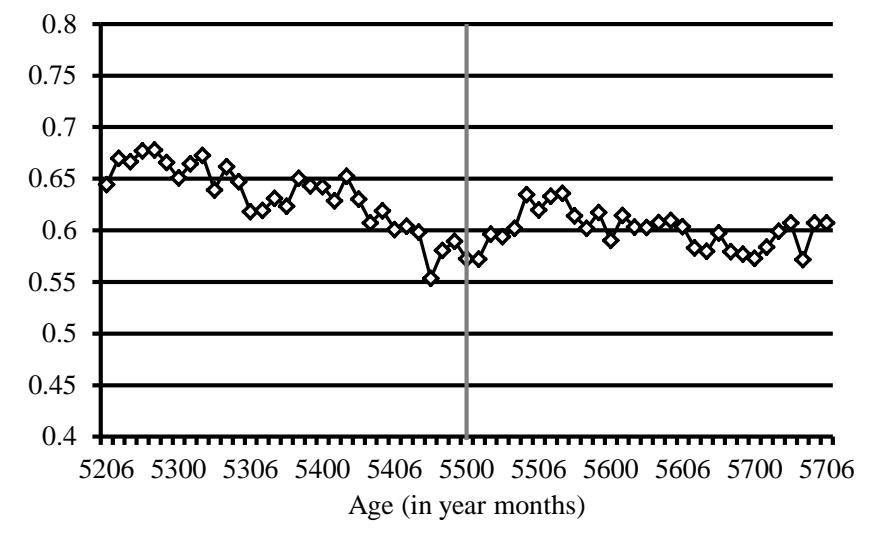


Figure A5: Sample Statistics by Age (Singaporeans around 50)

A. Bank account balance, by age

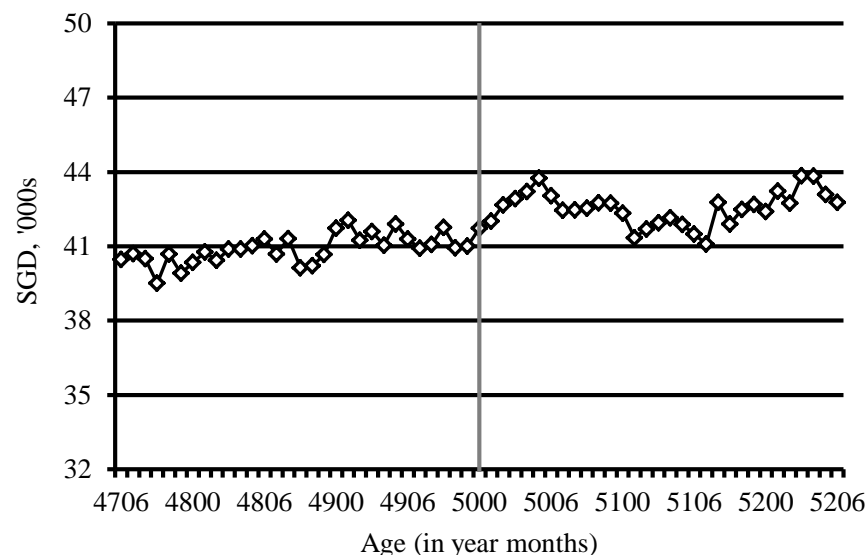

\section{Monthly credit card debt}

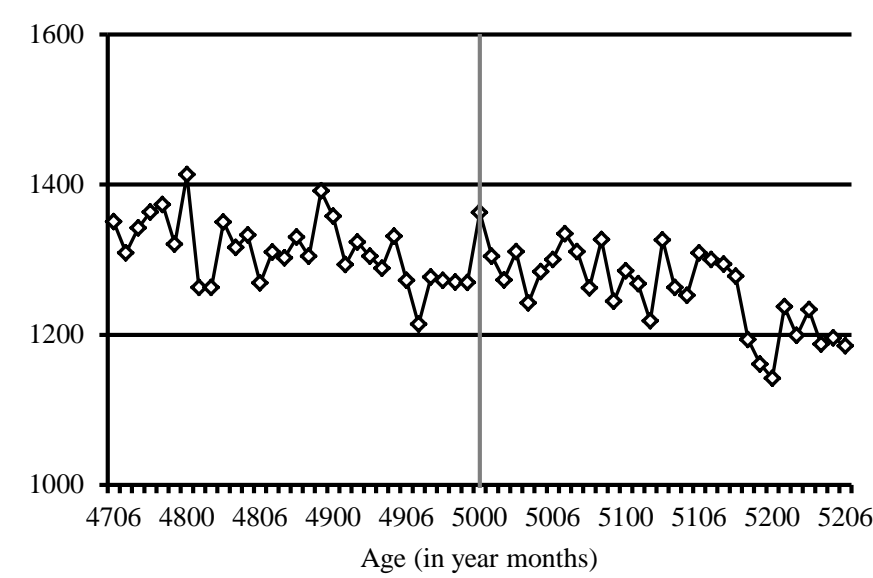

B. Total spending (Debit + Credit Card)

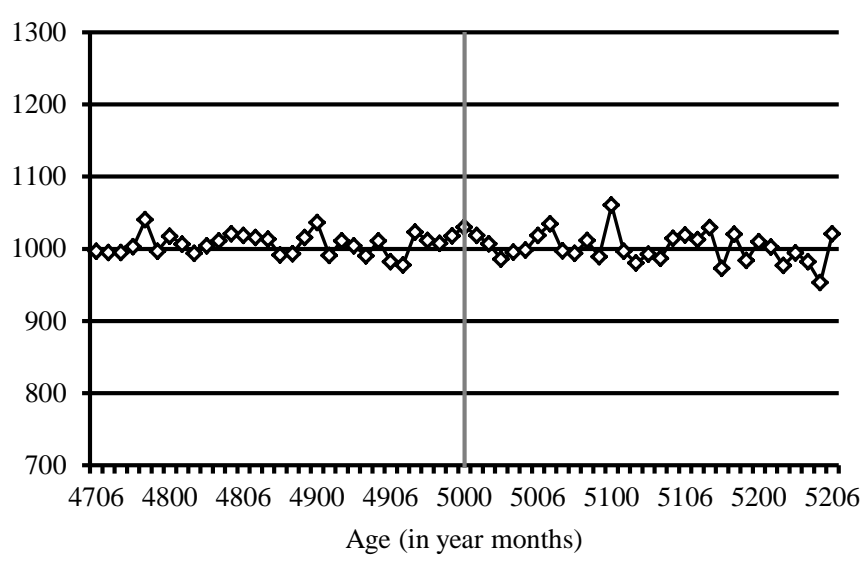

D. Monthly income

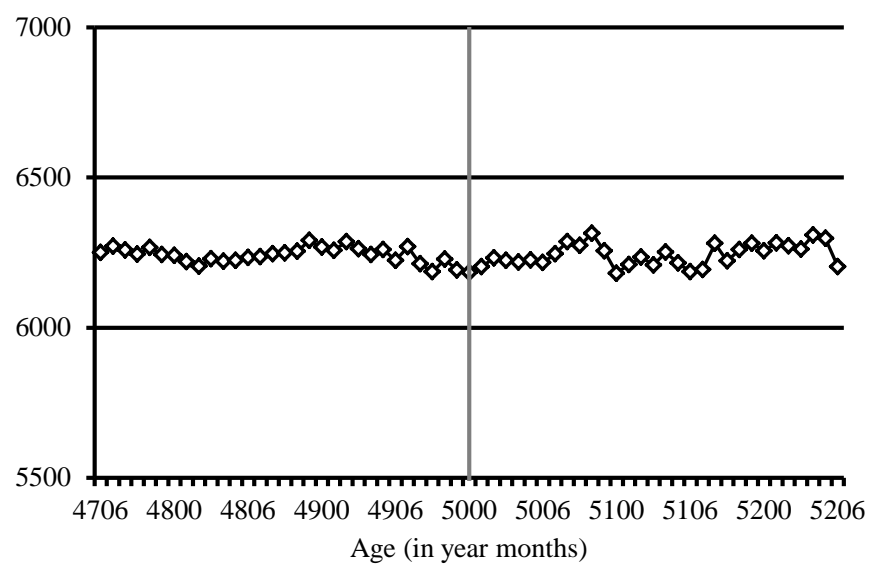

Note. Each panel plots the variable means by the age (in year-months). The sample includes all Singaporean individuals who turned 50 from April 2010 to March 2012. The vertical line indicates individuals in the sample who are age 50 and zero months. 


\section{E. Gender (\% female)}

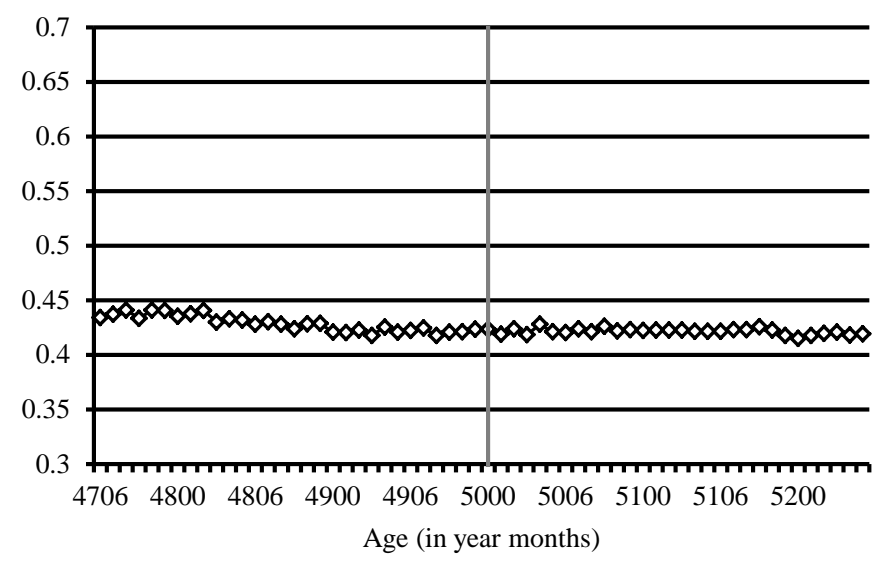

\section{G. Race (\% Chinese)}

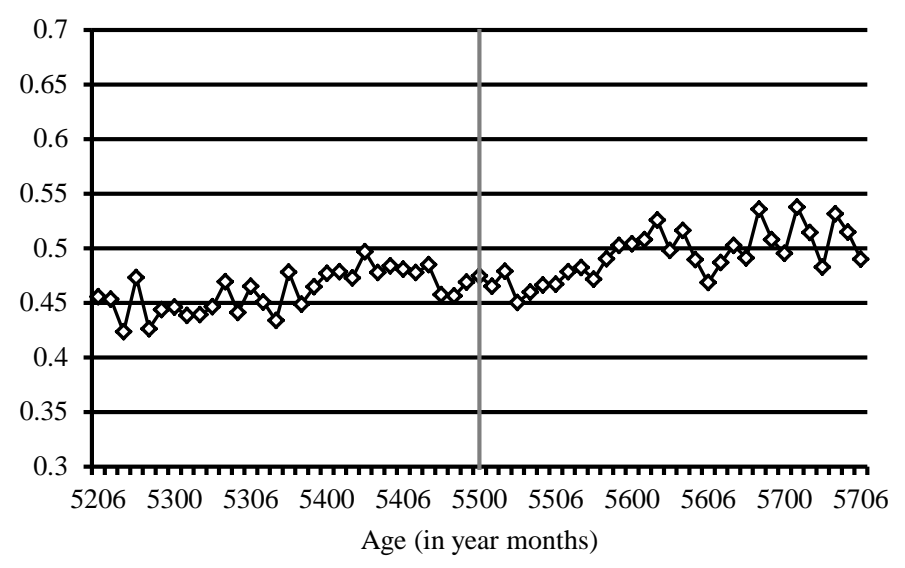

\section{F. Marital status (\% married)}

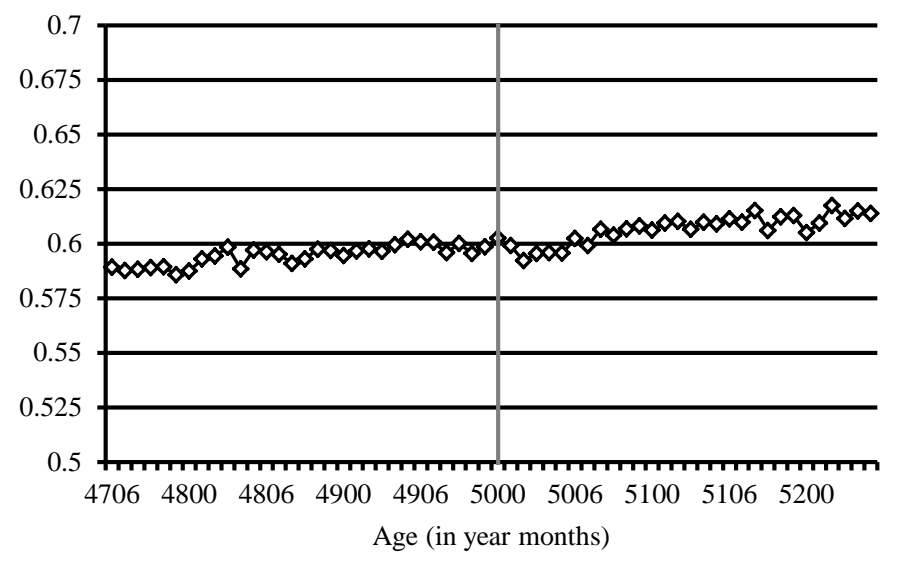


Table A1: Total Spending Response by Spending Category

\begin{tabular}{|c|c|c|c|c|c|c|c|c|}
\hline & $\begin{array}{c}\text { Supermarket } \\
(1) \\
\end{array}$ & $\begin{array}{c}\text { Service } \\
(2)\end{array}$ & $\begin{array}{c}\text { Dining } \\
(3) \\
\end{array}$ & $\begin{array}{c}\text { Entertainment } \\
(4) \\
\end{array}$ & $\begin{array}{c}\text { Apparel } \\
\text { (5) }\end{array}$ & $\begin{array}{c}\text { Travel } \\
(6)\end{array}$ & $\begin{array}{c}\text { Small } \\
\text { durables } \\
(7) \\
\end{array}$ & $\begin{array}{c}\text { Online } \\
(8) \\
\end{array}$ \\
\hline \multicolumn{9}{|l|}{ Before age 55} \\
\hline \multirow[t]{2}{*}{$(-3,-1$ month) window } & $6.08 * * *$ & $16.70^{*}$ & -0.16 & -1.57 & $14.75^{* *}$ & -1.68 & $12.77 * *$ & -0.05 \\
\hline & $(2.06)$ & (8.93) & $(3.43)$ & $(4.90)$ & $(6.12)$ & $(8.00)$ & $(5.78)$ & $(2.02)$ \\
\hline \multicolumn{9}{|l|}{ After age 55} \\
\hline \multirow[t]{2}{*}{ (0,12 months) window } & $7.72 * * *$ & $25.43^{* *}$ & 4.04 & 8.74 & $21.15^{* * *}$ & -12.33 & $23.90 * * *$ & 1.75 \\
\hline & $(2.72)$ & (11.89) & $(4.21)$ & $(6.80)$ & $(7.84)$ & (9.85) & $(7.60)$ & $(2.71)$ \\
\hline Observations & 46,979 & 46,979 & 46,979 & 46,979 & 46,979 & 46,979 & 46,979 & 46,979 \\
\hline R-squared & 0.511 & 0.388 & 0.353 & 0.675 & 0.283 & 0.297 & 0.190 & 0.437 \\
\hline
\end{tabular}

Note. Each column is a separate regression of the outcome on a dummy indicating individuals three months before they turn 55 and a dummy indicating individuals zero to 12 months after they turn 55. The effects are estimated relative to the omitted group that comprises individuals when they are at least four months prior to turning 55. The dependent variables are the monthly total card spending on supermarket, service, dining, entertainment, apparel, travel, small durable goods, and online for each individual in our sample. Merchant type descriptions are provided in the debit and credit card transactions, from which we group them into the above eight categories. All specifications include individual fixed effects and year*month fixed effects. Standard errors clustered at the individual level are reported in parentheses. ${ }^{* * *}$ significant at 1 percent, $* * 5$ percent, *1 percent. 
Table A2: Consumption Volatility Response

\begin{tabular}{|c|c|c|c|c|c|c|c|c|c|}
\hline & & \multicolumn{4}{|c|}{ Volatility in monthly consumption } & \multicolumn{4}{|c|}{ Range in monthly consumption } \\
\hline & & (1) & $(2)$ & $(3)$ & (4) & (5) & $(6)$ & $(7)$ & $(8)$ \\
\hline After age 55 & & $\begin{array}{c}-0.010 \\
(0.016)\end{array}$ & $\begin{array}{c}-0.030 \\
(0.027)\end{array}$ & $\begin{array}{c}-0.005 \\
(0.028)\end{array}$ & $\begin{array}{l}-0.020 \\
(0.026)\end{array}$ & $\begin{array}{c}-0.121^{*} \\
(0.067)\end{array}$ & $\begin{array}{l}-0.180 \\
(0.114)\end{array}$ & $\begin{array}{c}-0.093 \\
(0.114)\end{array}$ & $\begin{array}{l}-0.152 \\
(0.111)\end{array}$ \\
\hline After age 55 & & & 0.048 & & & & 0.156 & & \\
\hline After age 55 & $\begin{array}{l}\text { x Low credit limit } \\
\text { x High credit limit }\end{array}$ & & $\begin{array}{c}(0.040) \\
0.019 \\
(0.039)\end{array}$ & & & & $\begin{array}{c}(0.166) \\
0.040 \\
(0.159)\end{array}$ & & \\
\hline $\begin{array}{l}\text { After age } 55 \\
\text { After age } 55\end{array}$ & $\begin{array}{l}\text { x Low income } \\
\text { x High income }\end{array}$ & & & $\begin{array}{c}-0.007 \\
(0.041) \\
-0.006 \\
(0.038)\end{array}$ & & & & $\begin{array}{c}-0.018 \\
(0.166) \\
-0.067 \\
(0.159)\end{array}$ & \\
\hline $\begin{array}{l}\text { After age } 55 \\
\text { After age } 55\end{array}$ & $\begin{array}{l}\text { x Low bank balance } \\
\text { x High bank balance }\end{array}$ & & & & $\begin{array}{c}0.007 \\
(0.038) \\
0.025 \\
(0.040)\end{array}$ & & & & $\begin{array}{c}0.046 \\
(0.153) \\
0.046 \\
(0.169)\end{array}$ \\
\hline $\begin{array}{l}\text { Observations } \\
\text { R-squared }\end{array}$ & & $\begin{array}{l}4,512 \\
0.722\end{array}$ & $\begin{array}{l}4,512 \\
0.722\end{array}$ & $\begin{array}{l}4,512 \\
0.722\end{array}$ & $\begin{array}{l}4,512 \\
0.722\end{array}$ & $\begin{array}{l}4,510 \\
0.626\end{array}$ & $\begin{array}{l}4,510 \\
0.626\end{array}$ & $\begin{array}{l}4,510 \\
0.626\end{array}$ & $\begin{array}{l}4,510 \\
0.626\end{array}$ \\
\hline
\end{tabular}

Note. Each column is a separate regression of volatility in consumption on a dummy indicating individuals zero to 12 months after they turn 55 as well as its interaction with dummies indicating high and low liquidity consumers. Volatility (or variability) in consumption is computed, for each treated individual, in the pre-55 period and the post-55 period respectively (both periods follow the same definitions as previous tables). The dependent variable in the first four columns is defined as the standard deviation of monthly total card spending in the pre- or post-55 period scaled by the average total card spending amount during that same period. The dependent variable in the last four columns is defined as the difference between the highest monthly spending and the lowest monthly spending in the pre- or post-55 period, scaled by the average total card spending amount during the same period. High- and low- liquidity measures are defined in the same manner as those in Figure 3. All specifications include individual fixed effects. Standard errors clustered at the individual level are reported in parentheses. ***significant at 1 percent, **5 percent, *1 percent. 